\title{
ANISOTROPIC SMALL STRAIN ELASTIC PROPERTIES OF SANDS AND MIXTURE OF SAND-CLAY MEASURED BY DYNAMIC AND STATIC METHODS
}

\author{
A. Duttine ${ }^{\mathrm{i})}$, H. Di Benedetto ${ }^{\mathrm{ii}}$, D. Pham Van Bang ${ }^{\mathrm{iii}}$ and A. Ezaoui ${ }^{\mathrm{iv})}$
}

\begin{abstract}
A comprehensive series of triaxial compression (TC) tests have been performed on two air-dried poorly graded fine sands (Hostun and Toyoura sands) and on a moist mixture of sand and clay (Hostun sand-Kaolin clay). Tests were conducted by means of two high precision devices: a hollow cylinder apparatus (HCA, "T4C StaDy") and a triaxial apparatus (TA, "Triaxial StaDy"). The elastic properties of these granular materials were systemically and carefully measured at different stress levels by both static and dynamic methods, i.e., by small cyclic loadings for strain levels below $0.001 \%$ and by shear $(\mathrm{S})$ and compression $(\mathrm{P})$ wave propagations using piezoelectric elements. It is found that the elastic properties measured by static and dynamic methods become very consistent if the stress-induced anisotropy is properly taken into account. For this, two different assumptions were considered in the back analysis of the dynamic test interpretation: an isotropic elastic behaviour and a cross-anisotropic (or transverse isotropic) elastic behaviour. The resulting differences in the determination of each of the elastic parameters are quantified and discussed. An hypoelastic model (DBGS model), taking into account stress-induced anisotropy (including rotation of stress principal axes) is found to be relevant in the prediction of both static and dynamic measurements. This model was otherwise used to consider the cross-anisotropic elastic assumption.
\end{abstract}

Key words: anisotropy, dynamic, elasticity, sand, sand-clay mixture, small strain, static, triaxial compression tests (IGC: D6/D7)

\section{INTRODUCTION}

During the past decades, undeniable advances have been made in the laboratory testing methods for the accurate determination of soil properties at very low strain levels (typically less than $0.001 \%$ ). A number of local strain measurement systems have been developed in this respect, such as LDT at the University of Tokyo (Goto et al., 1991), inclinometers at the Imperial College of London (Burland and Symes, 1982; Ackerly et al., 1987) and non-contact transducers based devices (Hird and Yung, 1989; Hicher, 1996; Di Benedetto et al., 1997). Strains need to be measured locally, basically to avoid significant effects of bedding errors and system compliance (Tatsuoka and Shibuya, 1991; Lo Presti et al., 1993; Tatsuoka et al., 1994; Tatsuoka and Kohata, 1995). Soil properties are then determined mainly by static or "quasi-static" loadings in the sense that inertia forces can be neglected. In parallel, in terms of dynamic load- ings where inertia forces prevail, wave propagation measurement by the means of piezoelectric elements has spread considerably as these elements are easy to use and to implement on existing testing devices, while being cost effective. However, the interpretation of test results may be not so straightforward, and soil properties need to be obtained by back-analysis (Viggiani and Atkinson, 1995; Brignoli et al., 1996; Jardine et al., 1999; Kuwano, 1999; Modoni et al., 2000). These two methods may lead to significant differences in the determination of soil properties if a number of factors are not properly taken into account, such as the stress-induced anisotropy.

In this paper, based on a comprehensive set of experimental data, it is shown that the elastic properties inferred from static and dynamic loadings become remarkably consistent with each other if the stressinduced anisotropy is properly considered. When necessary, the appropriate assumption of a cross-anisotropic elastic behaviour must be considered in the back-analysis

i) Postdoctoral Fellow, Institute of Industrial Science, University of Tokyo, Japan (antoine@rs.noda.tus.ac.jp) (formerly of Department of Civil Engineering, DGCB-LGM, ENTPE, France).

ii) Professor, Department of Civil Engineering DGCB-LGM, ENTPE, France.

iii) Doctor and Research Engineer, Laboratoire National d'Hydraulique et d'Environnement, Equipe de recherche EDF-CETMEF, France (formerly at Department of Civil Engineering, DGCB-LGM, ENTPE, France).

iv) Ph.D Student, Department of Civil Engineering DGCB-LGM, ENTPE, France.

The manuscript for this paper was received for review on January 30, 2006; approved on January 15, 2007.

Written discussions on this paper should be submitted before January 1, 2008 to the Japanese Geotechnical Society, 4-38-2, Sengoku, Bunkyo-ku, Tokyo 112-0011, Japan. Upon request the closing date may be extended one month. 

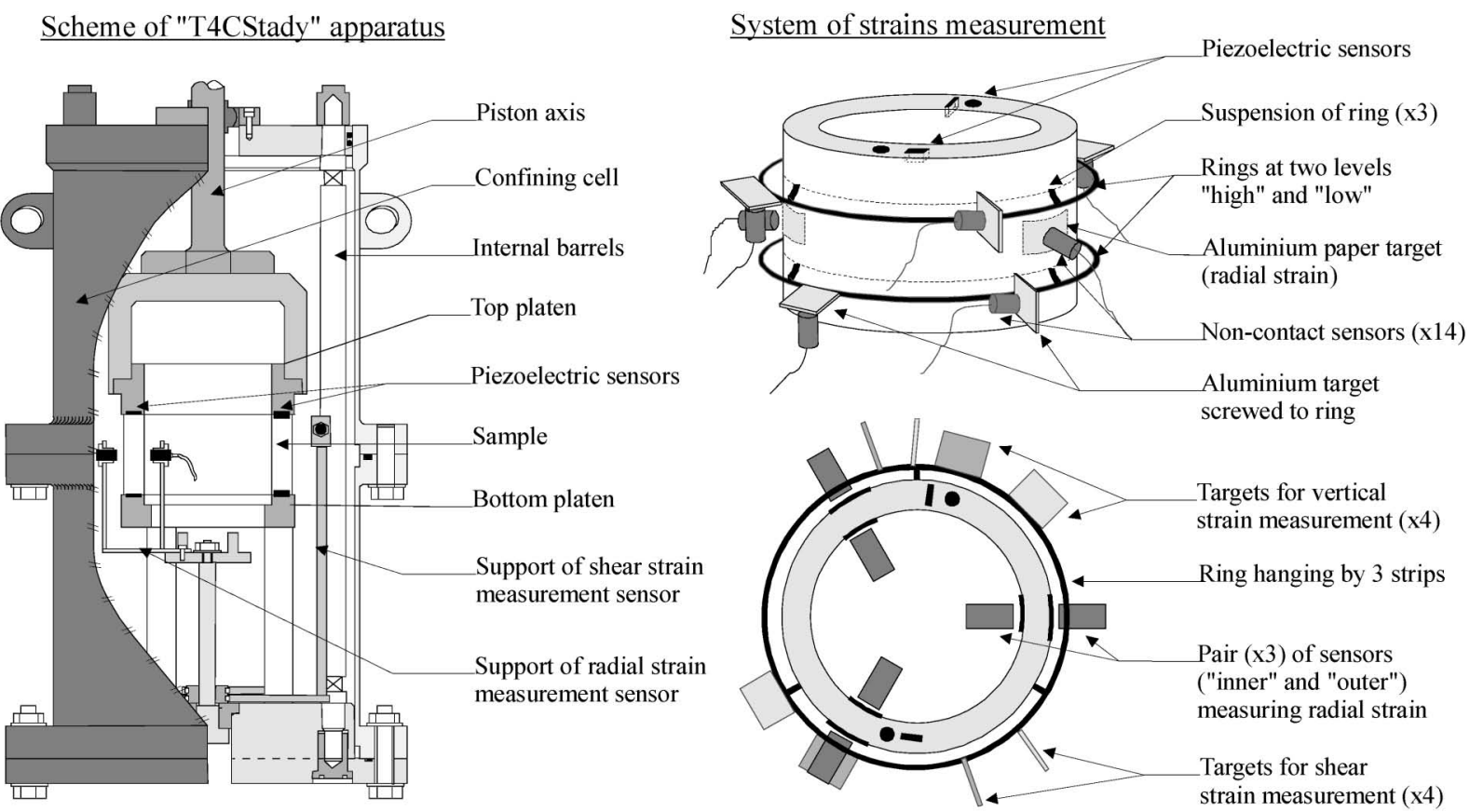

Fig. 1. Schematic view of the HCA "T4C StaDy" and of its system of strain measurement

of the dynamic test interpretation. It is shown that this assumption can be simply and easily considered without additional experimental measurements by means of a relevant anisotropic hypo-elastic model (DBGS model), which is found otherwise to be pertinent in the prediction of both static and dynamic measurements. Experimental data shown in this paper come from TC tests performed on two air-dried poorly graded fine sands, namely Hostun sand and Toyoura sand and on a moist mixture of Hostun sand and Kaolin clay. These tests were conducted with a HCA "T4C StaDy" and TA "Triaxial StaDy" with otherwise innovative local measurement systems. These apparatuses are described in TESTING APPARATUSES AND PROCEDURE. Details on the testing methods and procedure can also be found in this section. The materials elastic properties measured by static and dynamic methods (considering for the latter, an isotropic elastic behaviour) are compared in experimental results in the small strain elastic domain. A general anisotropic hypo-elastic formulation (DBGS-Di BenedettoGeoffroy-Sauzéat model, Di Benedetto et al., 2001) is presented in MODELLING whose simulations are confronted with experimental measurements. The anisotropic elastic assumption in the dynamic test interpretation is considered in COMPARISON BETWEEN A TRANSVERSE ISOTROPIC AND AN ISOTROPIC ELASTIC ASSUMED BEHAVIOUR and the differences obtained on each elastic parameter with the previously isotropic assumption (EXPERIMENTAL RESULTS IN THE SMALL STRAIN ELASTIC DOMAIN) are commented.

\section{TESTING APPARATUSES AND PROCEDURE}

\section{Testing Apparatuses}

The hollow cylinder sample in the HCA "T4C StaDy" (Fig. 1) has a $12 \mathrm{~cm}$ height, an outer diameter of $20 \mathrm{~cm}$ and an inner diameter of $16 \mathrm{~cm}$. Numerical analysis of stress and strain distributions in HCA (Hight et al., 1983; Sayao and Vaid, 1991) show that these dimensions allow to assume reasonable homogeneity of stress and strain within the sample. Two Neoprene membranes $(0.5 \mathrm{~mm}$ thickness) constitute the lateral sides while two rigid platens close the sample at the top and at the bottom. The top cap, connected to the press piston, is mobile in rotation and translation. Axial and torsional loadings are ensured by a servo-controlled hydraulic press (ref. Instron series 8500). Axial and shear load cells are incorporated in the piston. Accuracy in the measurement of axial and shear stresses can be estimated to $0.1 \mathrm{kPa}$ and $0.05 \mathrm{kPa}$ respectively. The identical inner and outer pressures are applied through vacuum inside the sample (for values up to $80 \mathrm{kPa}$ ) or by air pressure in the confining cell (for values up to $400 \mathrm{kPa}$ ). The specimen in the TA "Triaxial StaDy" (Fig. 2) has a $14 \mathrm{~cm}$ height and a $7 \mathrm{~cm}$ diameter. A $0.5 \mathrm{~mm}$ thick neoprene membrane is also used. Axial loading is applied by an electromechanical testing machine (ref. MTS DY36), which is controlled by closed loop feed back schemes on the measurements (axial stress or axial strain) obtained from filtered signals of the transducers. Output signals from the non-contact transducers and the internal load cell are filtered by a 4th order low pass analogical filter with a cut off frequency fixed at $7 \mathrm{~Hz}$. Accuracy in the measurement of axial stress can be estimated to less than $1 \mathrm{kPa}$. Confinement is also applied by vacuum (up to $80 \mathrm{kPa}$ ) and by air pressure in 


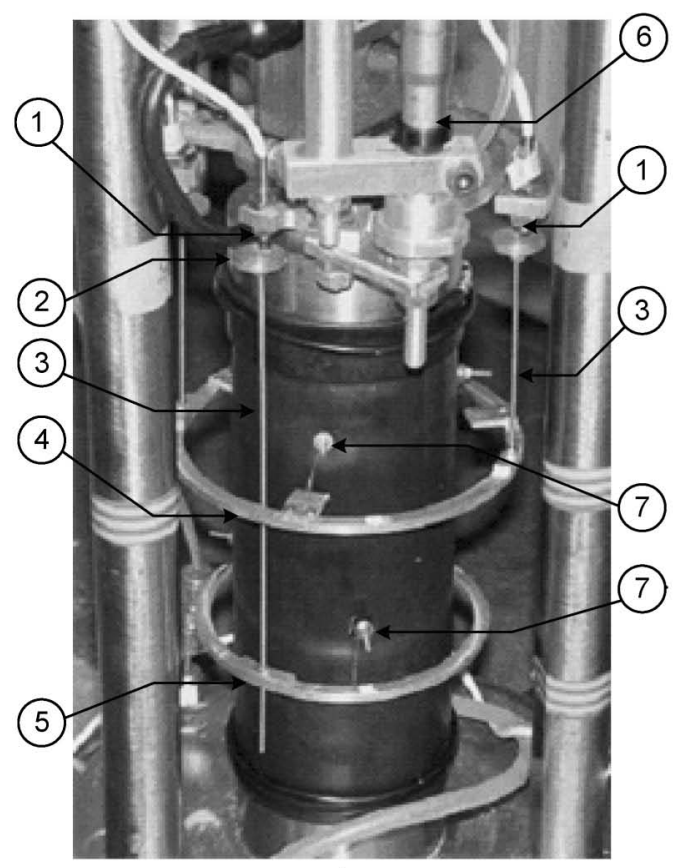

a)

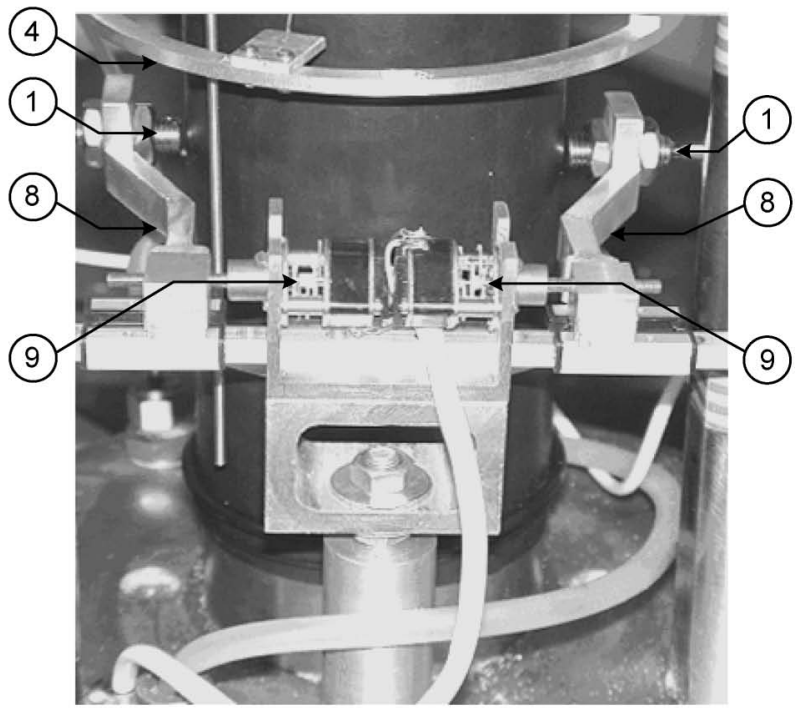

b)

Fig. 2. “Triaxial StaDy” apparatus: sample and system of local axial strain measurement (a), system of local radial strain measurement (b) (1. non-contact transducer, 2. target of non-contact transducer, 3. support of target, 4 . upper ring, 5 . lower ring, 6 . micrometric screw, 7 . fixation point of ring, 8. arm support of non-contact transducer, 9. micromotor)

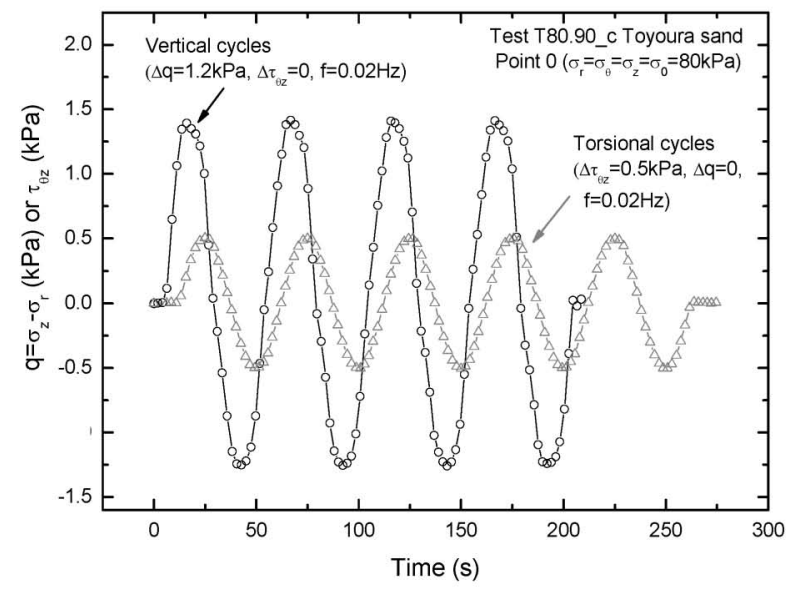

a)

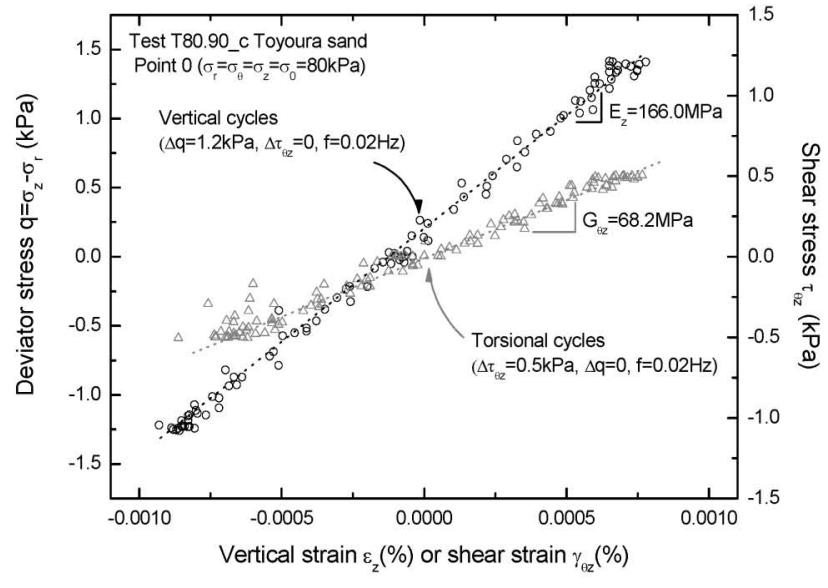

b)

Fig. 3. Example of small vertical and torsional cyclic loadings in the HCA “T4C StaDy" performed during test T80.90_c on air-dried Toyoura sand $\left(e_{0}=0.90 ; \sigma_{\mathrm{r}}=\sigma_{\theta}=\sigma_{\mathrm{z}}=\sigma_{0}=80 \mathrm{kPa}\right.$, test reported later in Fig. 8): stress history (a) and inferred Young's and shear moduli (b)

the confining cell (up to $400 \mathrm{kPa}$ ). An analogous set of air pressure regulators and analogical pressure transducers are used for both apparatuses with a resolution of 0.1 $\mathrm{kPa}$. Both apparatuses are also equipped with internal tie bars.

The local systems of strain measurement are similar between the HCA and TA (Figs. 1 and 2): vertical (respectively vertical and angular for the HCA) displacements are measured on two levels by two light rings in duralumin whose weight is less than $30 \mathrm{~g}$ and which are hung on 3 points of the membrane (respectively outer membrane) while carrying aluminium targets for non- contact transducers. Radial displacements (respectively outer and inner) are also measured by a set of non-contact transducers pointing through the membrane towards aluminium foils placed in between the specimen and the membrane. All non-contact transducers (ref. Micro Epsilon NCDT3010, $1 \mathrm{~mm}$ or $2 \mathrm{~mm}$ range) can be moved electronically or manually by micrometric screws. The resulting accuracies while in use and in terms of strain are estimated between $0.0003 \%$ and $0.0005 \%$ for both apparatuses. However, as an obvious counterpart, transducers need to be repositioned several times during testing. An example of small vertical and torsional cyclic 

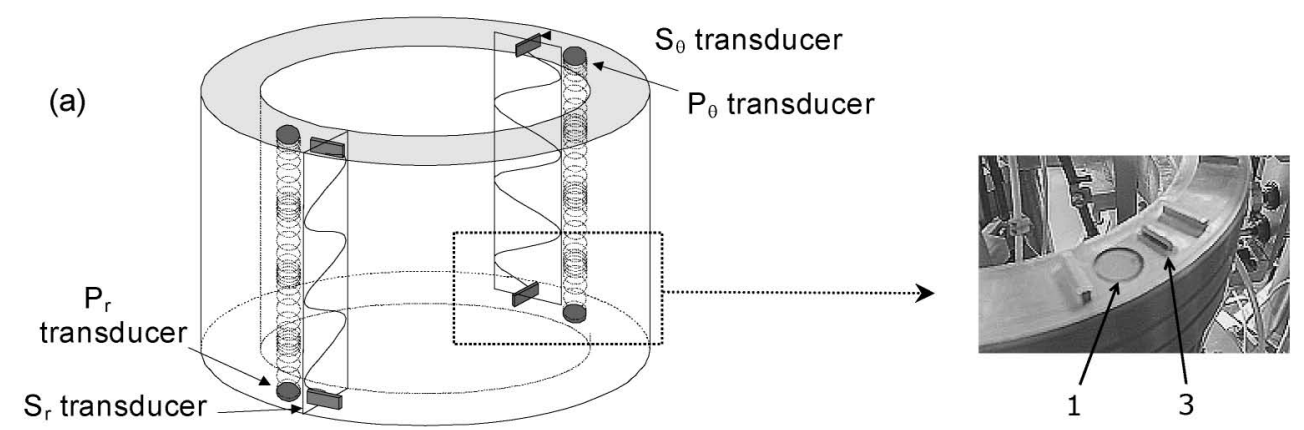

(b)
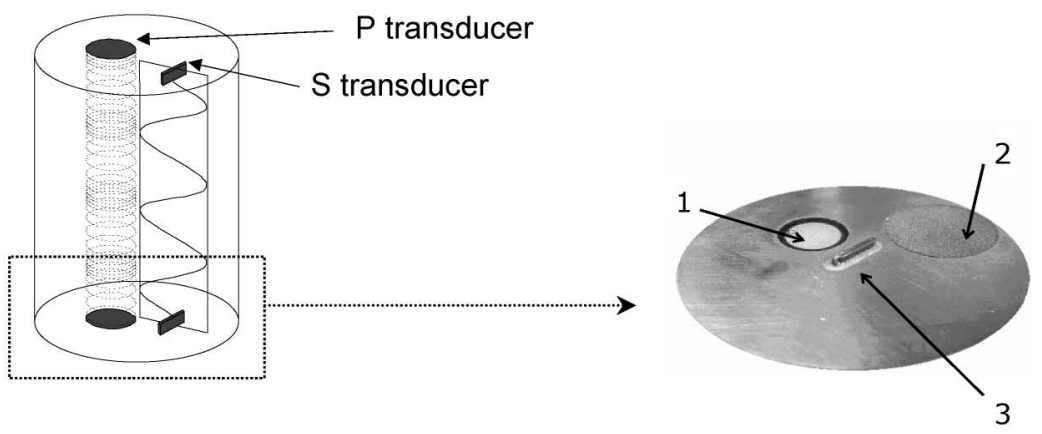

Fig. 4. Location of piezo-electric transducers in the HCA "T4C StaDy" (a) and in the TA "Triaxial StaDy" (b) (1. compression element, 2. porous stone, 3 . bender element)

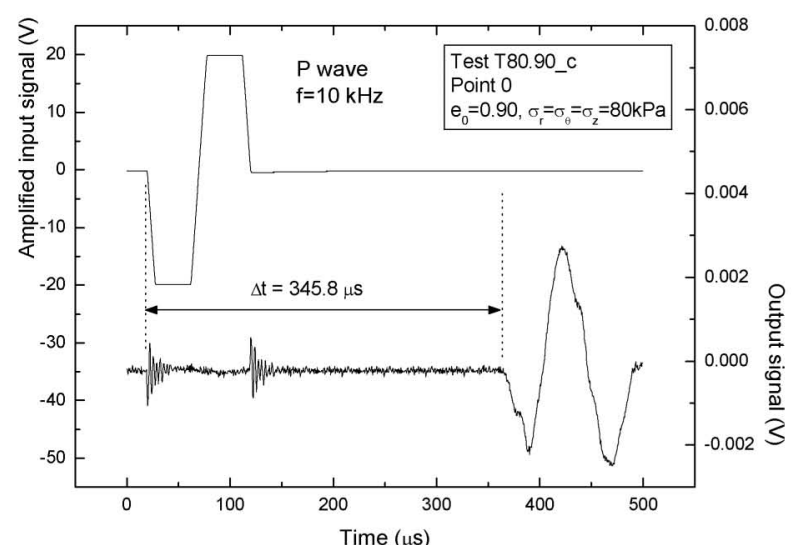

(a)

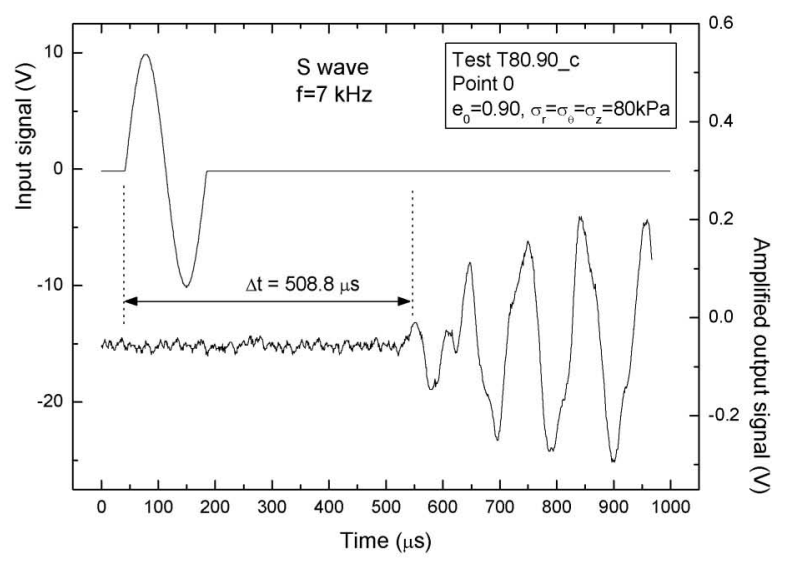

(b)

Fig. 5. Example of typical input (generated) and output (received) signals for $P$ wave (a) and $S$ wave (b) in case of the HCA: Single sinusoidal pulse frequency is $10 \mathrm{kHz}$ for $P$ wave (signal is troncated by the display on the oscilloscope) and $20 \mathrm{kHz}$ for $S$ wave in this example: Frequencies applied basically range from $5 \mathrm{kHz}$ to $100 \mathrm{kHz}$ to determine afterwards the relevant arrival time shown in these figures (test T80.90_c on airdried Toyoura sand $-e_{0}=0.90 ; \sigma_{\mathrm{r}}=\sigma_{\theta}=80 \mathrm{kPa}-$ reported later in Fig. 8)

loadings is given in Fig. 3 in case of the HCA. From Fig. 3(a) may be seen the accurate respect of the sinusoidal shape and amplitude of cycles. In Fig. 3(b) are shown the determinations of the corresponding Young's and shear moduli. It should be emphasized that the accurate measurements of vertical, radial, orthoradial and shear strains in the HCA during otherwise vertical or torsional or even combined vertical-torsional cyclic loadings provide very useful information on the whole elastic tensor linking stress and strain increments (Di Benedetto, 1997; Di Benedetto et al., 1999; Duttine, 2005).

Both apparatuses are also equipped with analogous sets of piezoelectric sensors (compression elements and bender elements provided by ISMES-Bergamo, Italy) located in each platen (details in Fig. 4). Piezoelectric elements are part of a dynamic testing chain composed of a function generator, a power amplifier (for the emission of $\mathrm{P}$ waves and the reception of $\mathrm{S}$ waves) and an oscilloscope (resolution of $2 \mu \mathrm{s}$ in time and $2 \mathrm{mV}$ in voltage). Output signals are averaged based on 256 single sinusoidal pulses at a global frequency of $10 \mathrm{~Hz}$. Tests are repeated for a frequency of the sinusoidal pulse itself ranging from $5 \mathrm{kHz}$ to $100 \mathrm{kHz}$ to detect the relevant arrival time of the wave (Fig. 5). Wave velocities are then determined based on the corresponding wave travel time 
Table 1. Grading characteristics of Hostun and Toyoura sands used in the present study

\begin{tabular}{lccccccc}
\hline Passing & \multicolumn{3}{c}{ Diameter $(\mathrm{mm})$} & \multicolumn{3}{c}{ Coefficients } & \multicolumn{2}{c}{ Void ratios } \\
\hline & $D_{10}{ }^{*}$ & $D_{30}{ }^{*}$ & $D_{60}{ }^{*}$ & $C_{\mathrm{u}}{ }^{* *}$ & $C_{\mathrm{c}}^{* *}$ & $e_{\min }{ }^{* * *}$ & $e_{\max }{ }^{* * *}$ \\
Hostun & 0.26 & 0.32 & 0.37 & 1.42 & 1.06 & 0.648 & 1.041 \\
Toyoura & 0.13 & 0.17 & 0.20 & 1.33 & 1.02 & 0.605 & 0.977 \\
\hline
\end{tabular}

${ }^{*} D_{\mathrm{x}}$ defined by x $\%$ passing particle size

** Coefficient of uniformity: $C_{\mathrm{u}}=D_{60} / D_{10}$ and coefficient of curvature: $C_{\mathrm{c}}=\left(D_{30}\right)^{2} /\left(D_{10} D_{60}\right)$

${ }^{* * *}$ Hostun: after Flavigny et al. (1990), Toyoura: data provided by Kitami Institute of Technology, Japan

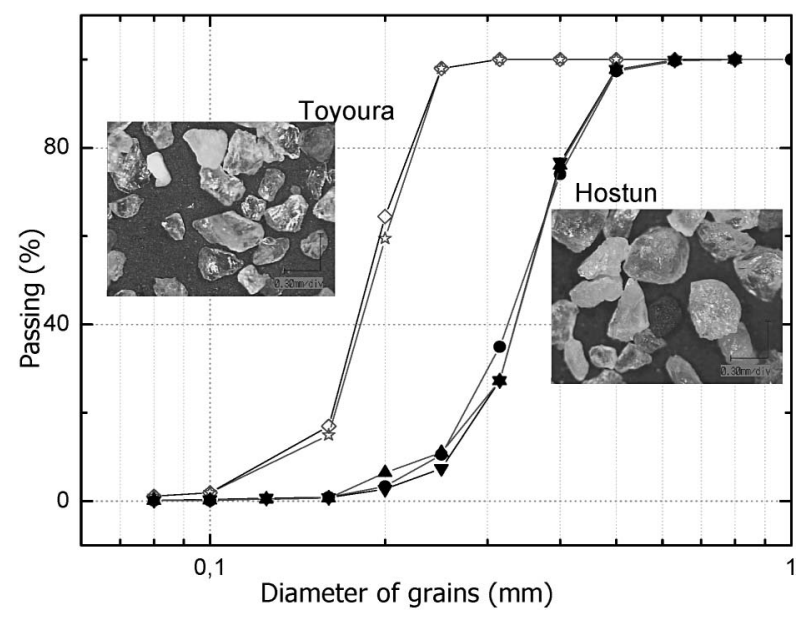

Fig. 6. Gradings of Hostun and Toyoura sands batches used in the present study and view of particle shapes (1div. $=0.3 \mathrm{~mm}$ )

and the current height of the sample, diminished by the sinking length of bender elements for $\mathrm{S}$ waves.

\section{Tested Materials and Sample Preparation}

Tested materials include two air-dried poor graded fine sands (Hostun and Toyoura sands) and a moist mixture of Hostun sand and Kaolin clay (M15). Hostun and Toyoura sands are quartz dominated sands whose grading curves are shown in Fig. 6 (characteristics on Table 1). Particle shapes classified as sub-angular to angular can also be seen on this figure.

The M15 sand/clay mixture is composed by $15 \%$ of Kaolin clay $\left(w_{1}=35 \%, \mathrm{PI}=14 \%\right)$ and $85 \%$ of Hostun sand (by dry weight) and by an initial global water content of $4.5 \%$. For an initial global void ratio of 0.98 (defined as the ratio of the volume of void-water plus air-by the volume of clay and sand solid grains), preliminary conducted monotonic loading TC tests on standard Bishop \& Henkel type TA have shown that this material exhibits a low apparent cohesion of $15.2 \mathrm{kPa}$, which is likely to be overestimated and a maximum friction angle of $30.5^{\circ}$, which appears to be slightly lower than for air-dried Hostun sand $\left(33.5^{\circ}\right)$ obtained during approximately the same conditions (Duttine, 2005).

Samples of M15 mixture in the HCA are filled following 6 sub-layers with height and mass controlled and deposit using spoon. Tamping and vibration methods
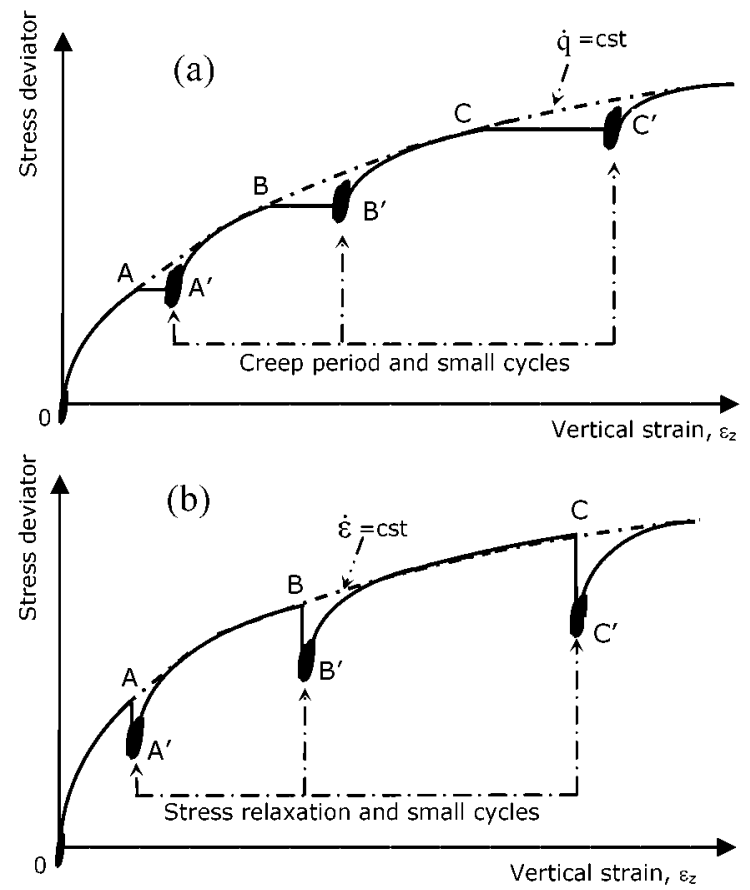

(c)

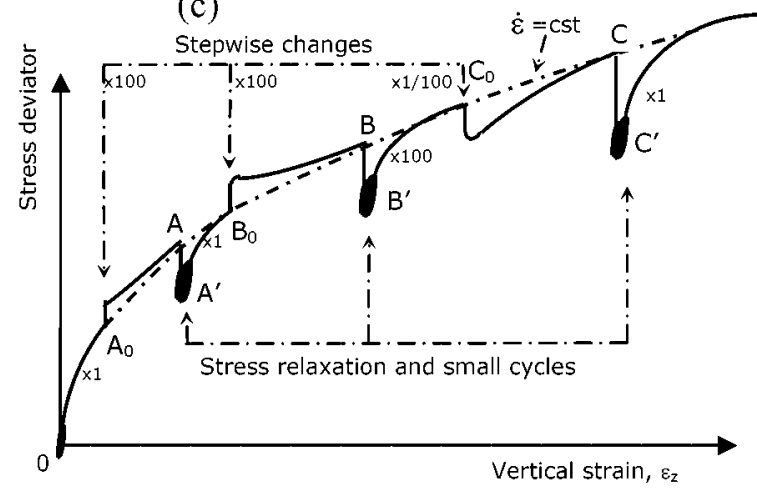

Fig. 7. Schematic global loading curves of drained TC tests performed in this study: Test with creep periods (a), test with stress relaxation periods (b), tests with stepwise changes in the strain rate (c)

are used to reach a lower single fabric void ratio $\left(e_{0}=\right.$ $0.98 \sim 0.99)$. Concerning air-dried sands, deposit is made by air pluviation (through constant height) in both HCA and TA and the same tamping and vibration methods are used to consider two types of granular packing after fabrication: loose $\left(D_{\mathrm{r}} \approx 28 \%\right.$ and $25 \%$, respectively for Hostun and Toyoura sand) and dense (resp. $D_{\mathrm{r}} \approx 82 \%$ and $90 \%$ ). Moulds are removed while applying a partial vacuum pressure of $20 \mathrm{kPa}$ within the sample. Samples are then isotropically consolidated to the desired confining pressure ranging from $55 \mathrm{kPa}$ up to $400 \mathrm{kPa}$.

\section{Experimental Campaign}

Figure 7 summarizes the types of drained TC tests performed in the different experimental campaigns. From the initial isotropic stress state, four steps are repeated successively:

i) the sample is vertically loaded at constant stress rate (Fig. 7(a)) or constant strain rate (Fig. 7(b)) or at 


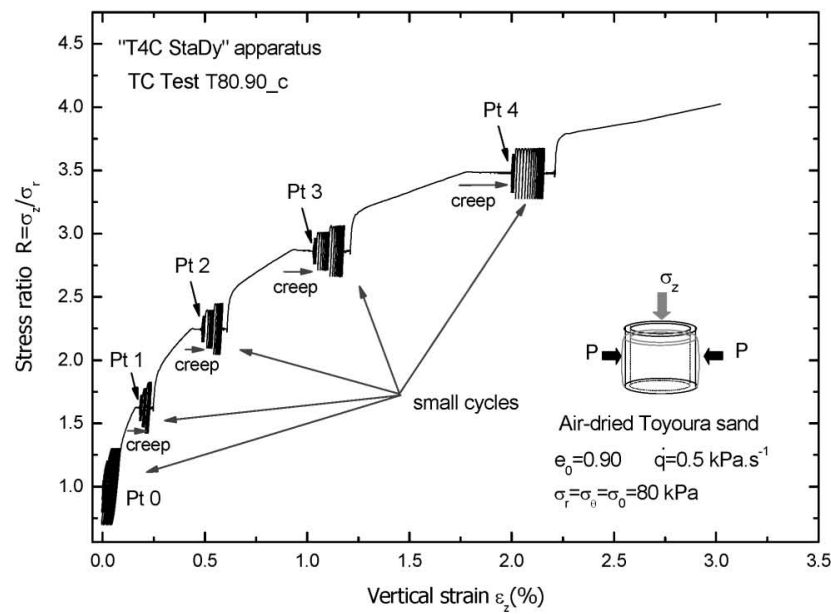

a)

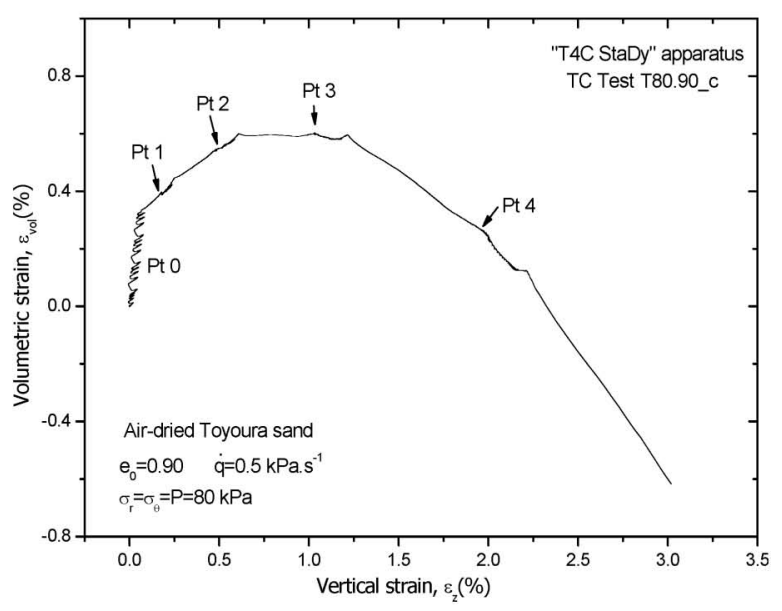

b)

Fig. 8. TC test including creep periods on air-dried Toyoura sand $\left(e_{0}=0.90 ; \sigma_{\mathrm{r}}=\sigma_{\theta}=\sigma_{0}=80 \mathrm{kPa}\right)$ performed with the HCA "T4C StaDy": stress ratio-vertical strain relationship (a) and volumetric strain-vertical strain relationship (b)

variable strain rate (Fig. 7(c)) until an 'investigation stage' is reached (point $\mathrm{A}, \mathrm{B}$ or $\mathrm{C}$ );

ii) then, a creep (or relaxation) period is imposed for an approximate duration of 3 hours $\left(\mathrm{AA}^{\prime}, \mathrm{BB}^{\prime}\right.$ or $\mathrm{CC}^{\prime}$ in Fig. 7);

iii) small quasi-static cyclic loading (vertical and/or torsional for the HCA "T4C StaDy") are applied after the creep (or relaxation) period (at points $\mathrm{A}^{\prime}, \mathrm{B}^{\prime}$ or $\mathrm{C}^{\prime}$ in Fig. 7);

iv) $\mathrm{P}$ and $\mathrm{S}$ waves propagations are performed.

Only creep tests (i.e., Fig. 7(a)) could be conducted with the HCA "T4C StaDy" on air-dried Toyoura sand and on M15 mixture whereas all 3 types of tests were carried out with the TA "Triaxial StaDy" on air-dried Hostun sand (i.e., Figs. 7(a), (b) and (c)). Moreover, considering only M15 TC tests, the number of investigation stages was intentionally limited in order to avoid the influence of important elapsing time which could induce water content evolution and create cementation (degree of saturation was roughly constant during the tests, $S_{\mathrm{r}} \approx 12.0 \%$ ).

A total of 40 tests were performed: 7 on Toyoura sand (3 on loose specimens, 4 on dense specimens, for a total of 37 investigation stages), 4 on M15 mixture (i.e., 11 investigation stages) and 29 on Hostun sand (14 on loose specimens, 15 on dense specimens, i.e., 251 investigation stages).

Figure 8 gives an example of respectively typical stress ratio-strain relationship and corresponding volumetric strain-vertical strain relationship for a test with creep periods (TC test T80.90_c performed on air-dried Toyoura sand $e_{0}=0.90, \sigma_{\mathrm{r}}=\sigma_{\theta}=\sigma_{0}=80 \mathrm{kPa}$-with the HCA "T4C StaDy"). At the different investigation stages, it can be noted that cyclic loadings were repeated with different amplitudes. This provides otherwise useful information about the limit elastic tensor and its degradation with strain amplitude (Di Benedetto et al., 1999; Duttine, 2005). However, in this paper, only the basic small strain properties (elastic moduli and Poisson's ratio for strain amplitudes below $0.001 \%$ ) are considered and analyzed. Previous studies (Di Benedetto et al., 1997(a), (b), 2003, 2005; Tatsuoka et al., 1995, 1999; Duttine, 2005) revealed otherwise that a "quasi-elastic" behaviour can be considered as a good approximation within this domain. These elastic or rigorously "quasi-elastic"' properties are obtained from the small static cyclic loadings and dynamic loadings performed after creeps or stress relaxations in order to dissipate the viscous component of the material behaviour. In these conditions, preliminary results showed that no viscous properties (rate dependencies) have to be considered in this small strain domain (Di Benedetto et al., 2001, 2003; Duttine, 2005). Material viscous properties (creep, stress relaxation, stress jumps followed by decays with straining during stepwise changes in the strain rate) are out of the scope of this paper. Analysis and modelling of these sets of data can be found in Pham Van Bang et al. (2006) and Duttine et al. (2006).

\section{EXPERIMENTAL RESULTS IN THE SMALL STRAIN ELASTIC DOMAIN}

In this section are presented the results from the static small cyclic loadings and the results from dynamic loadings (wave propagations). Then a comparison in terms of "static" and "dynamic" elastic moduli (vertical Young's moduli and shear moduli) is drawn.

\section{Results from Static Small Cyclic Loading}

In order to gather all experimental data, the choice is made to plot the ratio of vertical Young's moduli $\left(E_{\mathrm{z}}\right)$ (obtained from the small cyclic loadings at each investigation stage, example in Fig. 3) divided by its initial value determined at the initial isotropic stress state $\left(E_{0}\right)$ (Fig. 9). In the same way the ratio $\left(G_{\theta z} / G_{0}\right)\left(G_{\theta z}\right.$ being determined by pure torsional small cycling performed with " $\mathrm{T} 4 \mathrm{C}$ 


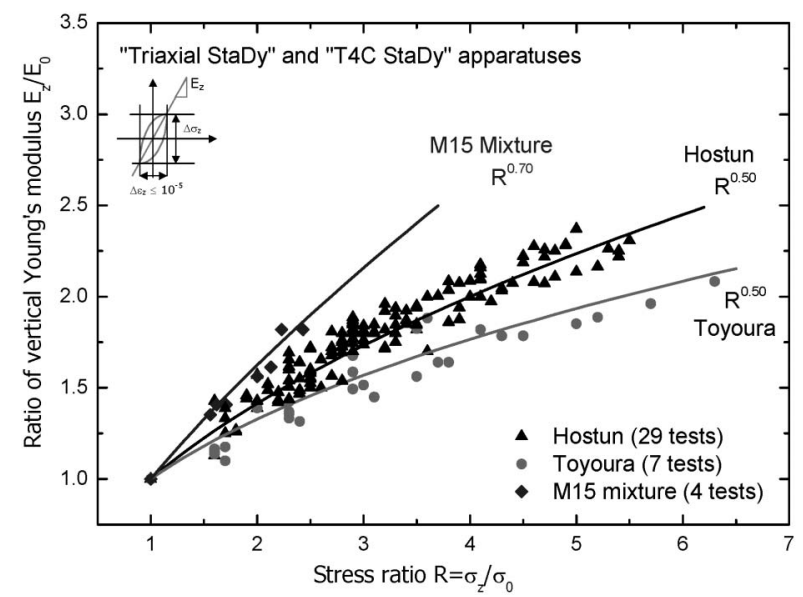

Fig. 9. Evolution of vertical Young's modulus $E_{\mathrm{z}} / E_{\mathbf{0}}$ in function of stress state $\sigma_{\mathrm{z}} / \sigma_{0}$ for all TC tests performed on air-dried Hostun, Toyoura sands and M15 mixture: $E_{0}$ and $\sigma_{0}$ are respectively the Young modulus and the vertical stress at the initial isotropic stress state

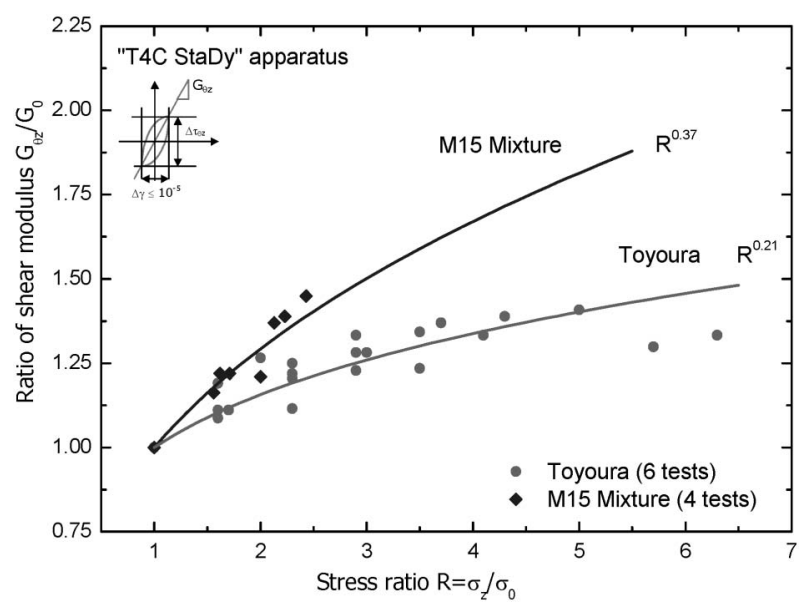

Fig. 10. Evolution of shear modulus $G_{\theta_{z}} / G_{0}$ in function of stress state $\sigma_{\mathrm{z}} / \sigma_{0}$ for TC tests performed on air-dried Toyoura sand and M15 mixture ("T4C StaDy" apparatus). $E_{0}$ and $\sigma_{0}$ are respectively the Young modulus and the vertical stress at the initial isotropic stress state

StaDy" apparatus such as in Fig. 3, while $G_{0}$ being the $G_{\theta z}$ value at the initial isotropic stress state) is plotted in Fig. 10 as a function of the stress state. Effects of void ratio's evolution are negligible during shearing considering the small variations of volumetric strain observed during the tests. From Figs. 9 and 10, it can be seen that the evolutions of Young's and shear moduli with stress ratio $\left(\sigma_{z} / \sigma_{0}\right)$ may be reasonably fitted by a power law function as $R^{\mathrm{m}}$, irrespectively of initial void ratio, and confining pressure. In addition, a ratio close to 2 can be noticed between the power coefficient $(m)$ for Young's and shear moduli. These results are in accordance with previous studies on the small strain properties of soils (Tatsuoka and Kohata, 1995; Stokoe et al., 1995; Hoque and Tatsuoka, 1998; Tatsuoka et al., 1997 .. among others). In case of M15 mixture, one may say that inter-

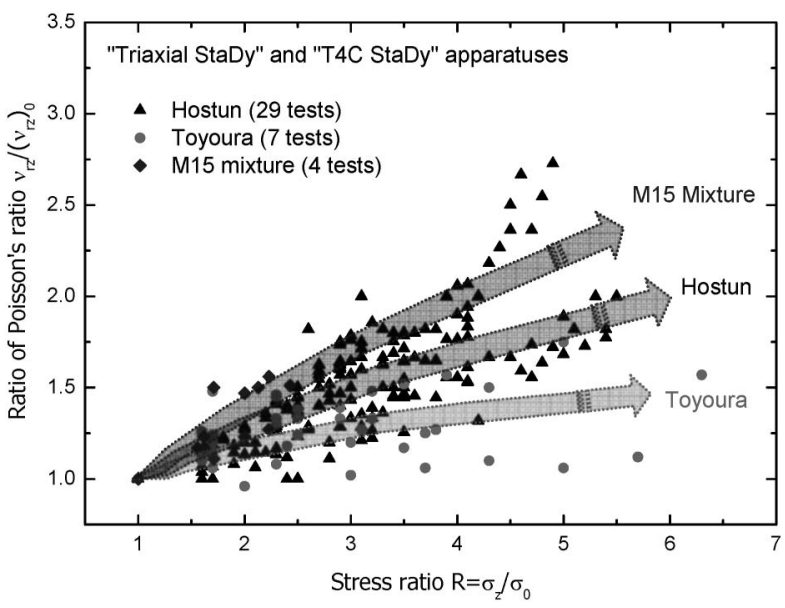

Fig. 11. Evolution of Poisson's ratio $v_{\mathrm{rz}} /\left(v_{\mathrm{rz}}\right)_{0}$ in function of stress state $\sigma_{\mathrm{z}} / \sigma_{0}$ for all TC tests performed on air-dried Hostun, Toyoura sands and M15 mixture: $\left(v_{\mathrm{rz}}\right)_{0}$ and $\sigma_{0}$ are respectively the Poisson's ratio and the vertical stress at the initial isotropic stress state

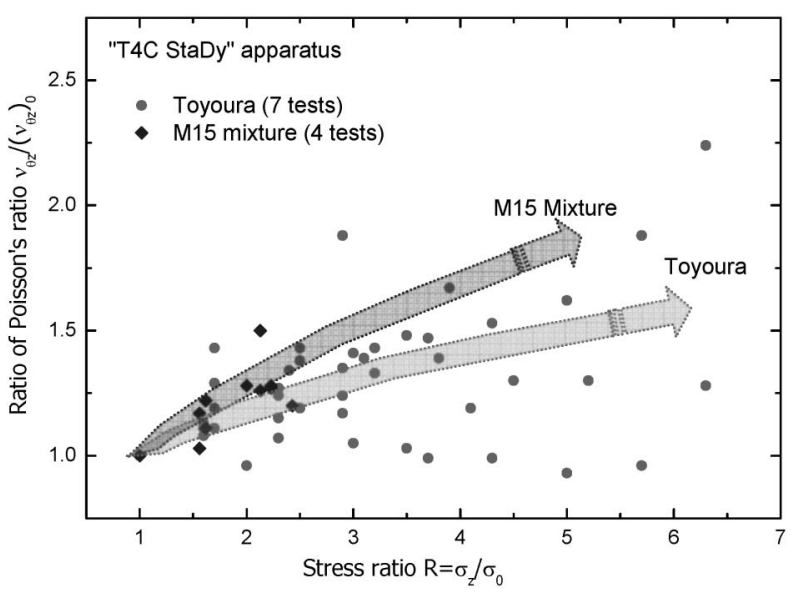

Fig. 12. Evolution of Poisson's ratio $v_{\theta z} /\left(v_{\theta z}\right)_{0}$ in function of stress state $\sigma_{\mathrm{z}} / \sigma_{0}$ for TC tests performed on air-dried Toyoura sand and M15 mixture ("T4C StaDy" apparatus) $\sigma_{0}$ and $\left(v_{\theta z}\right)_{0}$ are respectively the vertical stress and the Poisson's ratio at the initial isotropic stress state

particle contacts reinforced by suction and clay content are probably responsible for a higher $m$ value.

In Figs. 11 and 12, for tests performed on "T4C StaDy" apparatus only, are reported respectively the evolutions of Poisson's ratio $v_{\mathrm{rz}}=-\partial \varepsilon_{\mathrm{r}} / \partial \varepsilon_{\mathrm{z}}$ and $v_{\theta \mathrm{z}}=$ $-\partial \varepsilon_{\theta} / \partial \varepsilon_{\mathrm{z}}$, i.e. the ratios $\left(v_{\mathrm{rz}}\right) /\left(v_{\mathrm{rz}}\right)_{0},\left(v_{\theta \mathrm{z}}\right) /\left(v_{\theta \mathrm{z}}\right)_{0}$ (where $\left(v_{\mathrm{rz}}\right)_{0}$ and $\left(v_{\theta \mathrm{z}}\right)_{0}$ are the corresponding Poisson's ratios at the initial isotropic stress state) similarly in function of the stress state characterized by the stress ratio, $R$. Since Poisson's ratios are determined by a ratio of strains, incertitude is high due to the low applied strain level. It can be estimated around 30 to $40 \%$ considering our experimental devices. This explains the large scattering of data in Figs. 11 and 12. However, a tendency of increasing $\left\{v_{\mathrm{rz}} ; v_{\theta \mathrm{z}}\right\}$ values with shearing may be seen. Consistent similar results were obtained from true TC tests per- 


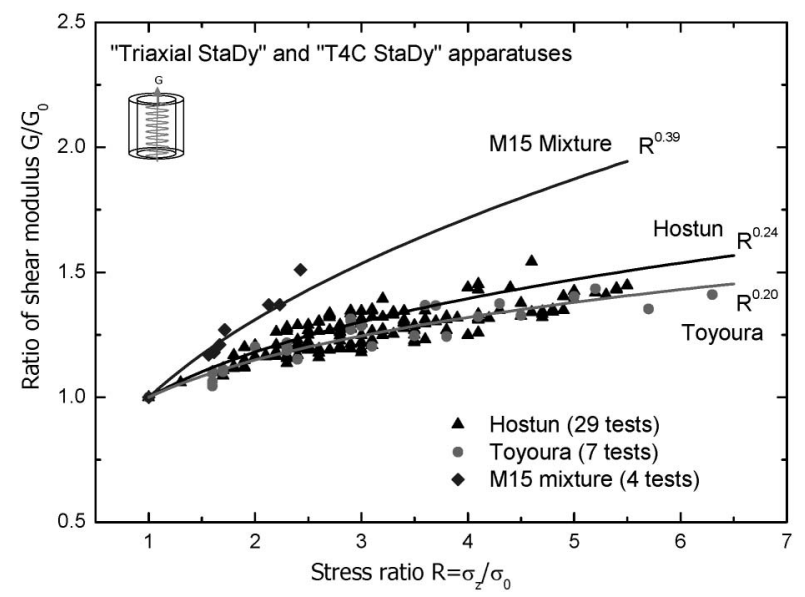

Fig. 13. Evolution of shear modulus $G / G_{0}$ (determined from wave propagation tests) with stress state $\sigma_{\mathrm{z}} / \sigma_{0}$ for all TC tests performed on air-dried Hostun, Toyoura sand and M15 mixture (to be compared with Fig. 10 corresponding to static small cycles analysis): $G_{0}$ and $\sigma_{0}$ are respectively the shear modulus and the vertical stress at the initial isotropic stress state

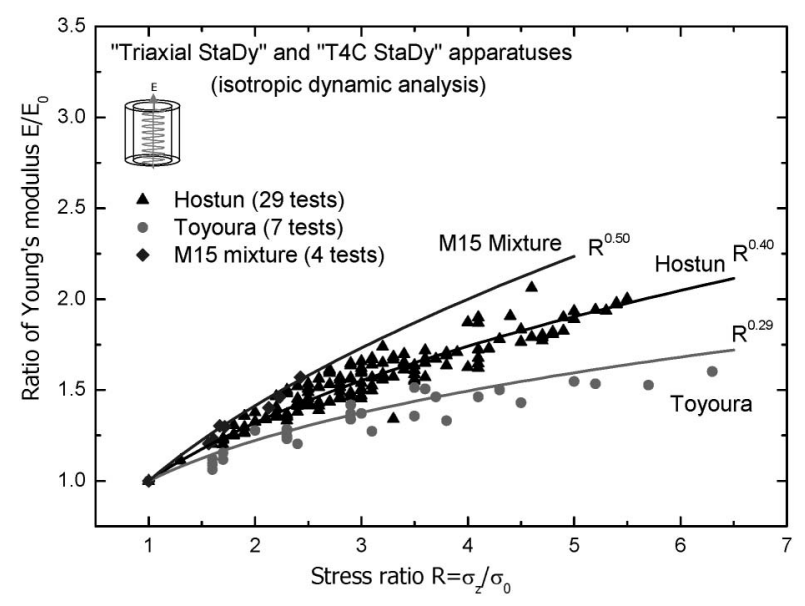

Fig. 14. Evolution of Young's modulus $E / E_{0}$ (determined from wave propagation tests and assumed isotropic behaviour) with stress state $\sigma_{\mathrm{z}} / \sigma_{0}$ for all TC tests performed on air-dried Hostun, Toyoura sands and M15 mixture (to be compared with Fig. 9 corresponding to static small cycles analysis): $E_{0}$ and $\sigma_{0}$ are respectively the Young modulus and the vertical stress at the initial isotropic stress state

formed on Toyoura sand by Hoque (1996) and Hoque and Tatsuoka (1998).

These features (increasing values of $E_{\mathrm{z}}$ as $\sigma_{\mathrm{z}}^{\mathrm{m}}$, of $G_{\theta z}$ as $\sigma_{z}^{\mathrm{m} / 2}$ and increasing values of Poisson's ratios) are especially taken into account in the anisotropic hypoelastic modelling (DBGS model) presented in MODELLING.

\section{Results from Dynamic Loadings}

Wave propagation tests performed at each investigation stage provide values of compression wave velocities $\left(c_{\mathrm{p}}\right)$ and shear wave velocities $\left(c_{\mathrm{s}}\right)$ deduced from corresponding wave travel times. However, to link these sets of data to conventional soil behaviour parameters, back-

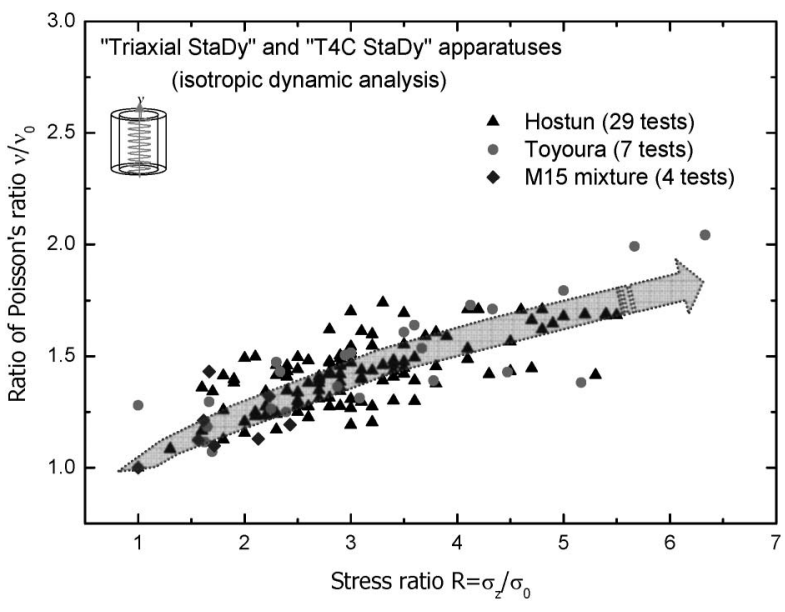

Fig. 15. Evolution of Poisson's ratio $v / v_{0}$ (determined from wave propagation tests and assumed isotropic behaviour) with stress state $\sigma_{\mathrm{z}} / \sigma_{0}$ for all TC tests performed on air-dried Hostun, Toyoura sands and M15 mixture (to be compared with Fig. 11 corresponding to static small cycles analysis): $v_{0}$ and $\sigma_{0}$ are respectively the Poisson's ratio and the vertical stress at the initial isotropic stress state

analysis is needed and an assumption concerning soil behaviour is required. Firstly, a "traditional" assumption is to consider the soil behaviour as isotropic elastic, which gives the following equations between wave velocities and elastic parameters:

$$
\begin{gathered}
G=\rho c_{\mathrm{s}}^{2} \quad E=2(1+v) G \\
v=\frac{\left(c_{\mathrm{p}} / c_{\mathrm{s}}\right)^{2}-2}{2\left(c_{\mathrm{p}} / c_{\mathrm{s}}\right)^{2}-2}
\end{gathered}
$$

where $\rho$ is the soil density $\left(\mathrm{kg} \cdot \mathrm{m}^{-3}\right)$.

In Figs. 13 and 14 are therefore plotted respectively the deduced evolutions of shear and Young's moduli $(G ; E)$, from Eqs. (1) to (3), with stress ratio. It may be seen that the power law functions inferred for the shear modulus are in a quite good accordance with the statically inferred ones (Results from Static Small Cyclic Loading). On the other hand, significant differences are obtained between the static and dynamic determinations of the Young's modulus. A more direct comparison between the Young and shear moduli determined from static small cyclic and dynamic loadings is drawn in the next section.

It has also to be noted that the "dynamic" Poisson's ratio determined from Eq. (3), increases with shearing (Fig. 15) similarly as Poisson's ratio determined by small cyclic loading. But attention needs to be attracted on the fact that this "dynamic" Poisson's ratio is an isotropic parameter since isotropic elastic behaviour is assumed. Typical initial values $\left(v_{0}\right)$ at the initial isotropic stress state ranges between 0.15 and 0.25 for the considered materials so that calculated dynamic $v$ reach high values close to incompressibility for higher stress ratios. This is not realistic and may be seen as a first suggestion that isotropic elastic behaviour may not be the most relevant assumption to be considered for the wave propagation tests analysis. 


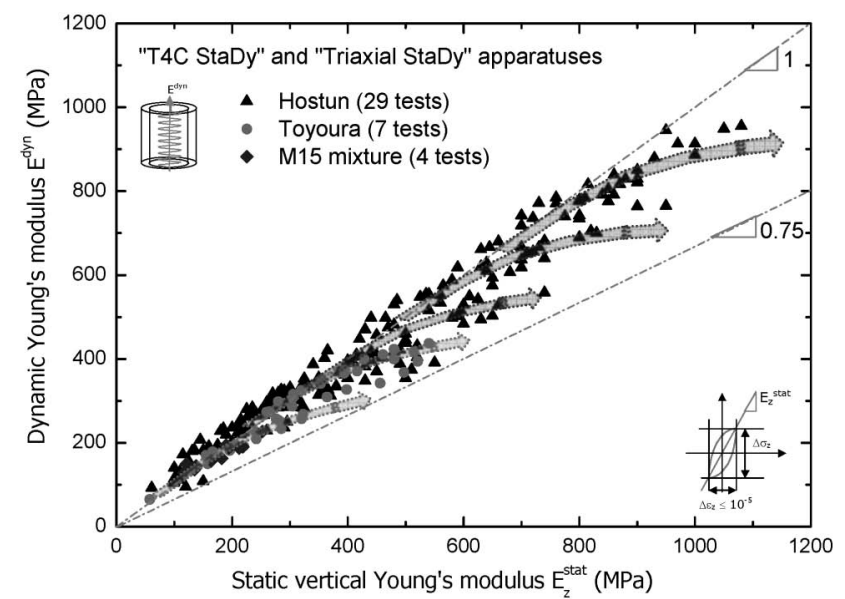

Fig. 16. Comparison between statically determined vertical Young's modulus $E_{\mathrm{z}}^{\text {stat }}$ and dynamically determined Young's modulus $E^{\text {dyn }}$ (isotropic elastic assumption) for all TC tests performed in this study

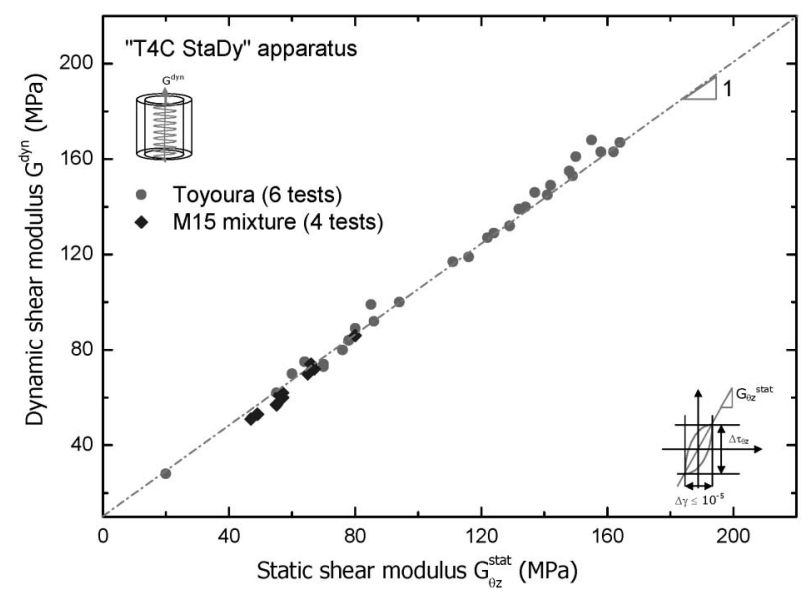

Fig. 17. Comparison between statically determined shear modulus $G_{\theta \mathrm{z}}^{\text {stat }}$ and dynamically determined shear modulus $G^{\mathrm{dyn}}$ (isotropic elastic assumption) for TC tests performed on "T4C StaDy", apparatus

\section{Comparison between Static and Isotropic Dynamic Elastic Moduli}

In the following, the vertical Young's modulus and the shear modulus determined from static small cyclic loadings will be noted respectively as $E_{z}^{\text {stat }}$ and $G_{\theta z}^{\text {stat }} .\left\{E^{\text {dyn }}\right.$; $\left.G^{\text {dyn }}\right\}$ will stand for the isotropic elastic moduli inferred from wave propagation tests (Eqs. (1) and (2)).

Figures 16 and 17 draw a direct comparison respectively between $\left\{E_{\mathrm{z}}^{\text {stat }} ; E^{\text {dyn }}\right\}$ and between $\left\{G_{\theta z}^{\text {stat }} ; G^{\text {dyn }}\right\}$ deduced from the corresponding tests. The inconsistency between the statically and dynamically (considering an isotropic elastic behaviour) determined Young's moduli may be confirmed from Fig. 16. The most significant differences, around 20 to $25 \%$, are obtained for high stress ratios. Indeed, one must notice that differences are actually small for low stress ratio values (close to isotropic stress states) and increase with stress ratio. This is illustrated by the dash arrows in Fig. 16 and may be responsible for the underestimation of power coefficient ( $m$ ) value in Fig. 14. That is to say that differences increase with shearing or in other words, with "more highly anisotropic" stress states. The assumption of an isotropic behaviour looks therefore as irrelevant as stress induced anisotropic behaviour becomes stronger. In the next section, a transverse isotropic behaviour which seems to be closer to the real soil behaviour will be considered. Note that the differences between dynamically and statically determined shear moduli do not seem to be affected by these considerations (Fig. 17). Results are in a very good accordance (maximum 5\% difference) irrespective of the value of stress ratio. This fact consolidates the suggestion of the use of a transverse isotropic behaviour since Eq. (1) remains the same if this anisotropic assumption is considered (see Application to Dynamic Loadings through Assumed Transverse Isotropic Elastic Behaviour).

Considering Poisson's ratios, incertitude is too high on the statically determined $\left\{v_{\mathrm{rz}}^{\text {stat }} ; v_{\theta \mathrm{z}}^{\text {stat }}\right\}$ Poisson's ratios to be carefully compared to dynamic isotropic Poisson's ratio $v^{\text {dyn }}$.

\section{MODELLING}

A general relationship between stress and strain increments inside the elastic domain is presented below. This rheological model is given by an hypo-elastic formulation. Within this framework is considered the DBGS model (Di Benedetto et al., 2001). Simulations for static and dynamic cases are then presented.

\section{DBGS Model}

General incremental form of a non-viscous (rateindependent) behaviour can be shown to be as follows (Darve, 1978):

$$
\delta \underline{\varepsilon}=\underline{\underline{M}}(h, \operatorname{dir}\{\delta \underline{\sigma}\}) \delta \underline{\sigma}
$$

where $\{\delta \underline{\varepsilon} ; \delta \sigma\}$ are the (non viscous) strain and stress increment vectors. $\underline{M}$ is the rheological compliance tensor. The introduction of $h$, history parameters (scalars, vectors or tensors) expresses stress history dependence and the introduction of the direction of stress increment $\operatorname{dir}\{\delta$ $\underline{\sigma}\}=\delta \underline{\sigma} /\left(\Sigma \delta \sigma_{\mathrm{ij}}^{2}\right)$ the irreversibility of behaviour.

Successively, Di Benedetto et al. (2001), Duttine (2005) showed experimentally for air-dried sands and sand/clay mixtures that $M$ can be assumed as independent of stress increment direction in the small strain domain, leading to the hypo-elastic Eq. (5):

$$
\delta \underline{\varepsilon}=\underline{\underline{M}}(h) \delta \underline{\sigma}
$$

Moreover, additional experimental results on air-dried sands exhibit a symmetrical compliance tensor $\underline{\underline{M}}$ (Duttine, 2005). As a consequence, the DBGS model suggests the following anisotropic (orthotropic) and symmetrical expression of tensor $M$ in the stress principal axes:

$$
M^{\mathrm{DBGS}}=\frac{1}{f(e)} \frac{S_{v} \Sigma_{\mathrm{p}}+{ }^{\mathrm{t}} S_{v}^{\mathrm{t}} \Sigma_{\mathrm{p}}}{2}
$$


with $f(e)$ a function of void ratio $(e)$. Note that the history parameter $h$ in Eq. (5) can be incorporated in the function $f(e)$. Its definition, however is out of the scope of this paper and basically, in all the following, the function $f(e)$ does not need to be determined. The superscript " $t$ " denotes the transpose function. $\left\{S_{\mathrm{v}} ; \Sigma_{\mathrm{p}}\right\}$ are the tensors originally defined by Hardin and Blandford (1989):

$$
\begin{gathered}
S_{\mathrm{v}}=\left[\begin{array}{cccccc}
1 & -v_{0} & -v_{0} & 0 & 0 & 0 \\
-v_{0} & 1 & -v_{0} & 0 & 0 & 0 \\
-v_{0} & -v_{0} & 1 & 0 & 0 & 0 \\
0 & 0 & 0 & 1+v_{0} & 0 & 0 \\
0 & 0 & 0 & 0 & 1+v_{0} & 0 \\
0 & 0 & 0 & 0 & 0 & 1+v_{0}
\end{array}\right] \\
\Sigma_{\mathrm{p}}=\left[\begin{array}{cccccc}
\frac{1}{\sigma_{1}^{\mathrm{m}}} & 0 & 0 & 0 & 0 & 0 \\
0 & \frac{1}{\sigma_{2}^{\mathrm{m}}} & 0 & 0 & 0 & 0 \\
0 & 0 & \frac{1}{\sigma_{3}^{\mathrm{m}}} & 0 & 0 & 0 \\
0 & 0 & 0 & \frac{1}{\sigma_{2}^{\mathrm{m} / 2} \sigma_{3}^{\mathrm{m} / 2}} & 0 & 0 \\
0 & 0 & 0 & 0 & \frac{1}{\sigma_{1}^{\mathrm{m} / 2} \sigma_{3}^{\mathrm{m} / 2}} & 0 \\
0 & 0 & 0 & 0 & 0 & \frac{1}{\sigma_{1}^{\mathrm{m} / 2} \sigma_{2}^{\mathrm{m} / 2}}
\end{array}\right]
\end{gathered}
$$

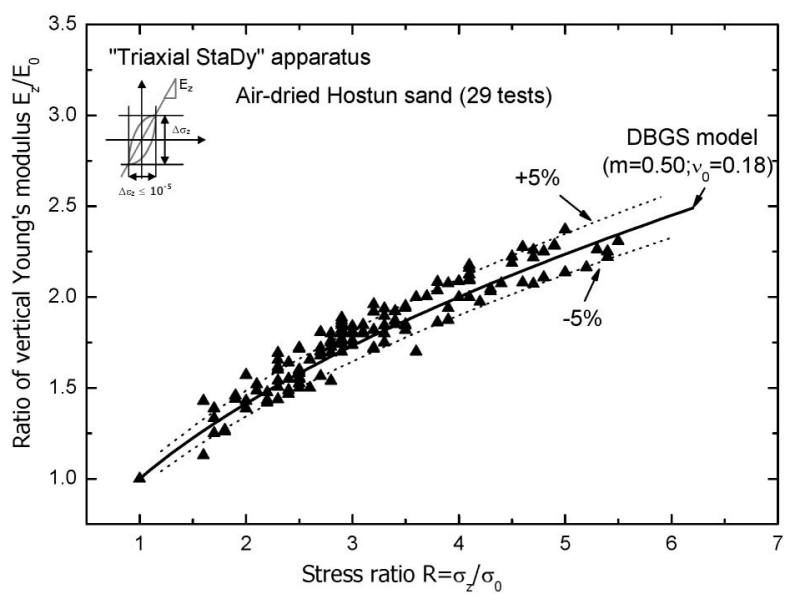

Fig. 18. Evolution of experimental static vertical Young's modulus $E_{\mathrm{z}} / E_{0}$ with stress ratio $R$ and DBGS simulations for all TC tests performed on air-dried Hostun sand ("Triaxial StaDy", apparatus): $E_{0}$ and $\sigma_{0}$ are respectively the Young modulus and the vertical stress at the initial isotropic stress state

the stress principal axes. For instance, as far as pure

where $\left\{m ; v_{0}\right\}$ are two constants and stand respectively for the power coefficient and the isotropic Poisson's ratio value at an isotropic stress state. $\left\{\sigma_{1} ; \sigma_{2} ; \sigma_{3}\right\}$ are the principal stress values, strictly positive as the model is formulated for cohesionless materials.

Note that expression (6) of $M^{\mathrm{DBGS}}$ tensor is valid only in torsional shear tests (from an initial isotropic or anisotropic stress state) are concerned, (sudden or continuous) rotation of principal axes from fixed sample axes are involved and rotation tensors are introduced in the $M^{\mathrm{DBGS}}$ expression becoming therefore much more complicated (see Duttine, 2005). Considering our tests conditions (TC tests), sample axes and stress principal axes remain the same so that expression (6) stays valid in the $r$, $\theta, z$ directions. Expression (6) can be rewritten unequivocally by Eq. (9). The considered vertical, horizontal Young's moduli, and shear modulus in the $(\theta ; z)$ plane are thus given by Eqs. (10) to (12). The concerned Poisson's ratios $\left\{v_{\mathrm{r} z} ; v_{\theta z}\right\}$ are expressed by Eq. (13).

$$
M^{\mathrm{DBGS}}=\frac{1}{f(e)}\left[\begin{array}{ccccc}
\frac{1}{\sigma_{\mathrm{r}}^{\mathrm{m}}} & \frac{-v_{0}}{2}\left(\frac{1}{\sigma_{\theta}^{\mathrm{m}}}+\frac{1}{\sigma_{\mathrm{r}}^{\mathrm{m}}}\right) & 0 & 0 \\
\frac{-v_{0}}{2}\left(\frac{1}{\sigma_{\mathrm{r}}^{\mathrm{m}}}+\frac{1}{\sigma_{\theta}^{\mathrm{m}}}\right) & \frac{1}{\sigma_{\theta}^{\mathrm{m}}} & 0 & 0 \\
\frac{-v_{0}}{2}\left(\frac{1}{\sigma_{\mathrm{r}}^{\mathrm{m}}}+\frac{1}{\sigma_{\mathrm{m}}^{\mathrm{m}}}\right) & \frac{-v_{0}}{2}\left(\frac{1}{\sigma_{\theta}^{\mathrm{m}}}+\frac{1}{\sigma_{\mathrm{z}}^{\mathrm{m}}}\right) & 0 & 0 \\
0 & 0 & 0 & 0
\end{array}\right]
$$




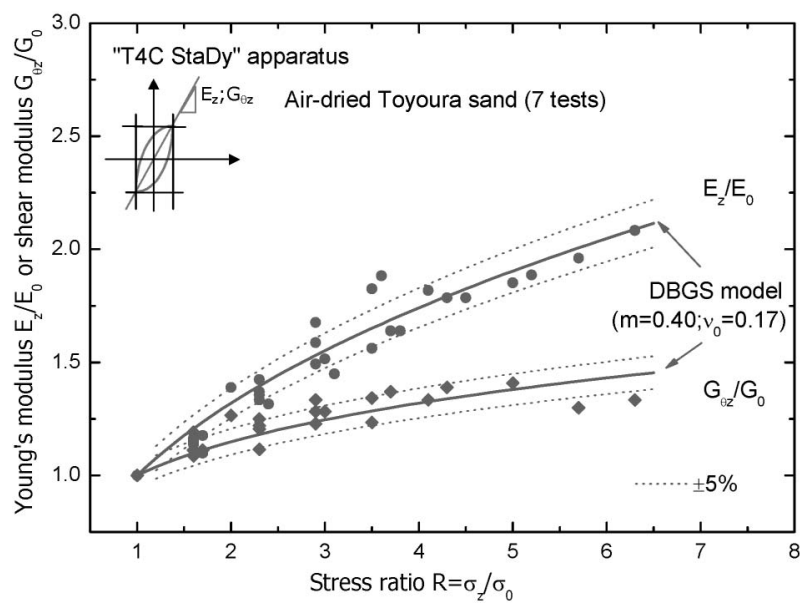

Fig. 19. Evolution of experimental static vertical Young's modulus $E_{\mathrm{z}} / E_{0}$ and experimental shear modulus $G_{\theta \mathrm{z}} / G_{0}$ with stress ratio, and DBGS simulations for all TC tests performed on air-dried Toyoura sand ("T4C StaDy" apparatus): $G_{0}$ and $\sigma_{0}$ are respectively the shear modulus and the vertical stress at the initial isotropic stress state

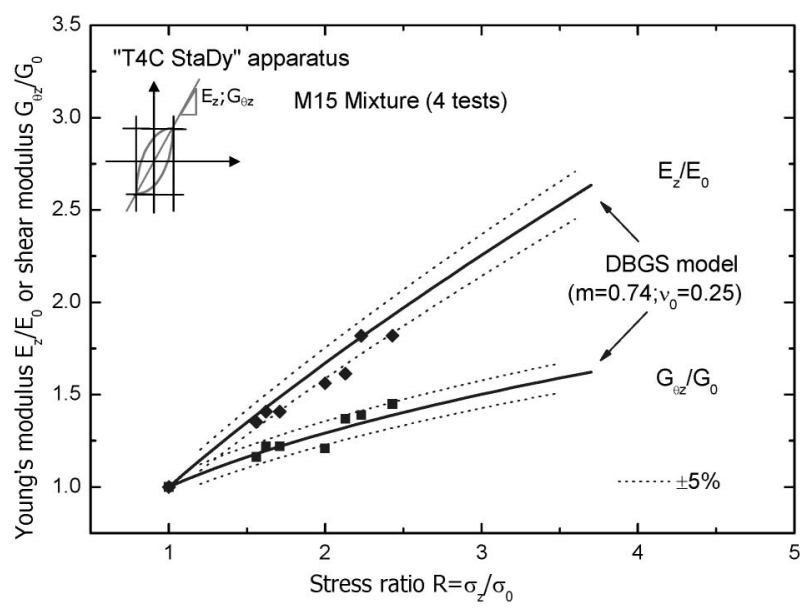

Fig. 20. Evolution of experimental static vertical Young's modulus $E_{\mathrm{z}} / E_{0}$ and experimental shear modulus $G_{\theta z} / G_{0}$ with stress ratio, and DBGS simulations for all TC tests performed on M15 mixture ("T4C StaDy" apparatus): $G_{0}$ and $\sigma_{0}$ are respectively the shear modulus and the vertical stress at the initial isotropic stress state

Keeping in mind that $\sigma_{\mathrm{r}}=\sigma_{\theta}=\sigma_{0}=P$. Thus,

$$
\begin{gathered}
E_{\mathrm{z}}=\frac{\partial \sigma_{\mathrm{z}}}{\partial \varepsilon_{\mathrm{z}}}=f(e) \sigma_{\mathrm{z}}^{\mathrm{m}} ; \quad E_{\mathrm{r}}=E_{\theta}=f(e) \sigma_{\mathrm{r}}^{\mathrm{m}} \\
G_{\theta \mathrm{z}}=\frac{\partial \tau_{\theta \mathrm{z}}}{\partial \gamma_{\theta \mathrm{z}}}=\frac{f(e)}{2\left(1+v_{0}\right)} \sigma_{\theta}^{\mathrm{m} / 2} \sigma_{\mathrm{z}}^{\mathrm{m} / 2} \\
v_{\mathrm{rz}}=\frac{\partial \varepsilon_{\mathrm{r}}}{\partial \varepsilon_{\mathrm{z}}}=v_{\theta \mathrm{z}}=\frac{\partial \varepsilon_{\theta}}{\partial \varepsilon_{\mathrm{z}}}=\frac{v_{0}}{2}\left(1+\frac{\sigma_{\mathrm{z}}^{\mathrm{m}}}{\sigma_{\mathrm{r}}^{\mathrm{m}}}\right) \\
v_{\mathrm{r} \theta}=v_{\mathrm{rr}}=\frac{\partial \varepsilon_{\mathrm{r}}}{\partial \varepsilon_{\theta}}=v_{0}
\end{gathered}
$$

For our tests conditions, $M^{\mathrm{DBGS}}$ tensor (expression (9)) becomes therefore transverse isotropic (symmetry around the vertical ' $z$ ' axis) and is totally determined by the function $f(e)$ and the 2 constants $\left\{m ; v_{0}\right\}$. As far as small

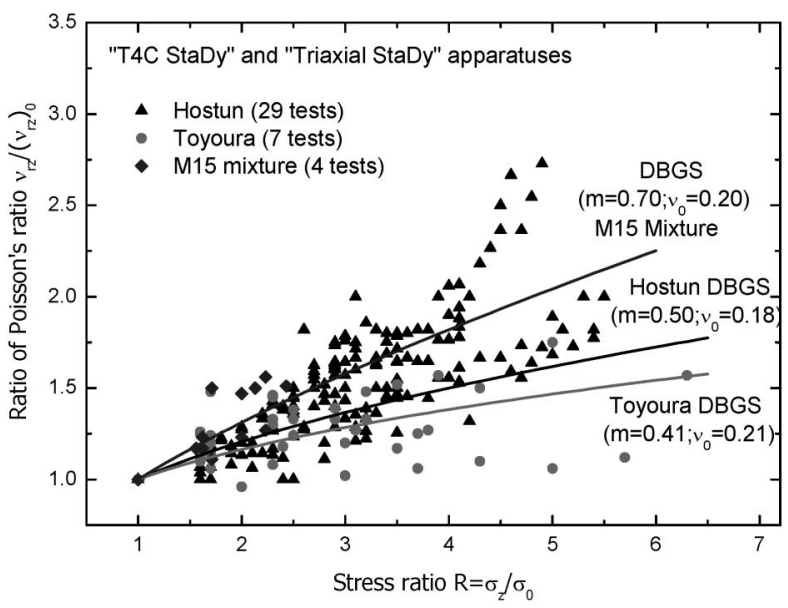

Fig. 21. Evolution of static Poisson's ratio $v_{\mathrm{rz}} /\left(v_{\mathrm{rz}}\right)_{0}$ with stress ratio $R$ and DBGS simulations for all TC tests performed on air-dried Hostun, Toyoura sands and M15 mixture: $\left(v_{\mathrm{rz}}\right)_{0}$ and $\sigma_{0}$ are respectively the Poisson's ratio and the vertical stress at the initial isotropic stress state

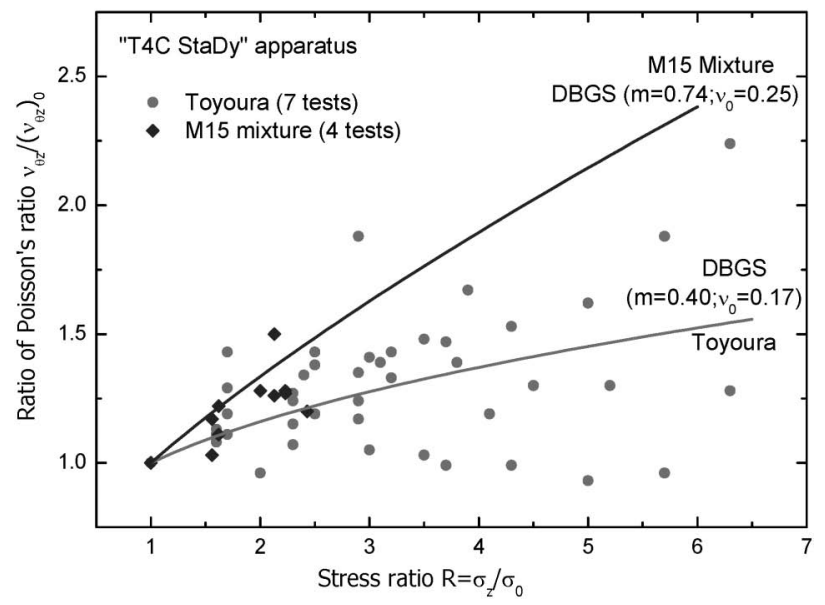

Fig. 22. Evolution of static Poisson's ratio $v_{\theta z} /\left(v_{\theta z}\right)_{0}$ with stress ratio $R$ and DBGS simulations for TC tests performed on air-dried Toyoura sand and M15 mixture ("T4C StaDy" apparatus): $\left(v_{\theta z}\right)_{0}$ and $\sigma_{0}$ are respectively the Poisson's ratio and the vertical stress at the initial isotropic stress state

static loadings are concerned, $m$ value may be inferred from vertical Young's modulus or shear modulus evolutions while shearing (Figs. 9 and 10). $v_{0}$ values may be deduced from average static Poisson's ratio values at the initial isotropic stress state. Finally $f(e)$, which can be considered as a constant for a considered test due to the low variation of volumetric strain, may be determined by initial Young's moduli values at different initial void ratio values and different confining pressures.

A proposition of extended DBGS model (DBGSP) integrating inherent and strain-induced anisotropy can be found in Pham Van Bang et al. (2006), Ezaoui et al. (2006) and will not be considered in this paper.

\section{Simulations (Static Loadings)}

DBGS model simulations of the evolutions of the 


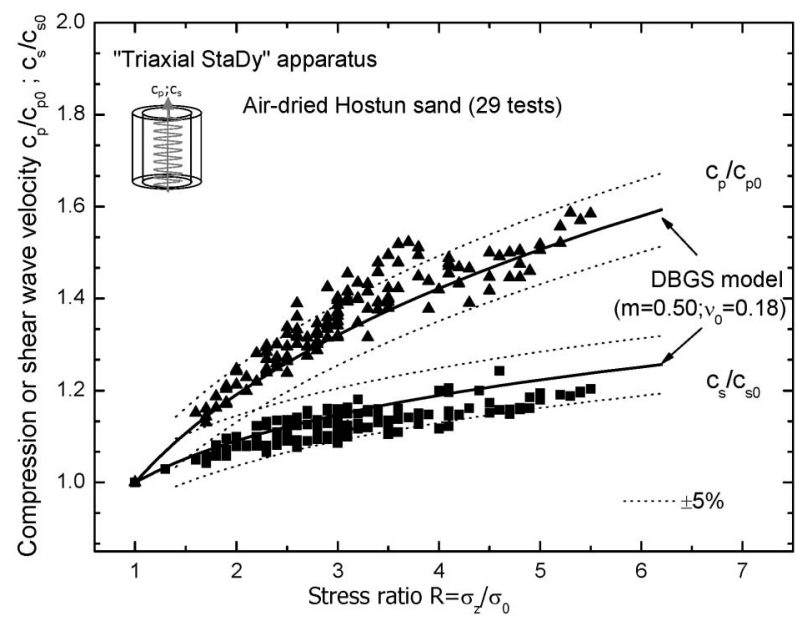

Fig. 23. Evolution of experimental compression and shear wave velocity $\left\{c_{\mathrm{p}} / c_{\mathrm{p} 0} ; c_{\mathrm{s}} / c_{\mathrm{s} 0}\right\}$ with stress ratio and simulations by DBGS model for TC tests performed on air-dried Hostun sand ("Triaxial StaDy" apparatus): $c_{\mathrm{p} 0} ; c_{\mathrm{s} 0}$ and $\sigma_{0}$ are respectively the compression, the shear wave velocity and the vertical stress at the initial isotropic state

vertical Young's modulus and shear modulus (both obtained in static conditions) are shown in Figs. 18, 19 and 20 respectively for air-dried Hostun sand, air-dried Toyoura sand and for M15 mixture. From these figures it may be seen that a good agreement is reached between simulations and experimental data for all these different materials. As shown in Fig. 20 and more extensively in Duttine (2005), the DBGS is still valid for the M15 mixture as a low apparent cohesion is exhibited by this material. For the evolution of Poisson's ratios (Figs. 21 and 22), scattering of experimental data (see Results from Static Small Cyclic Loading) prevents from drawing a quantitative conclusion. Yet, one should qualitatively notice that increasing tendency is roughly respected by the model.

\section{Application to Dynamic Loadings through Assumed Transverse Isotropic Elastic Behaviour}

The application of DBGS model to dynamic wave propagation tests should be considered within the framework of a transverse isotropic elastic behaviour assumption. Accordingly, the following relations between wave velocities and the five independent elastic parameters (see Eq. (21)) may be obtained (for waves propagating in the vertical ' $z$ ' direction defined as the symmetry axis of the transverse isotropic material):

$$
\begin{gathered}
\rho c_{\mathrm{p}}^{2}=\frac{E_{\mathrm{z}}\left(v_{\mathrm{r} \theta}-1\right)}{v_{\mathrm{r} \theta}-1+2 v_{\mathrm{rz}}^{2} E_{\mathrm{r}} / E_{\mathrm{z}}} \\
\rho c_{\mathrm{s}}^{2}=G_{\theta \mathrm{z}}
\end{gathered}
$$

As previously mentioned, the Eq. (15) linking shear wave velocity and shear modulus remains the same as Eq. (1) (established for an assumed isotropic elastic behaviour).

Incorporating Eqs. (10) to (13) into the former expres-

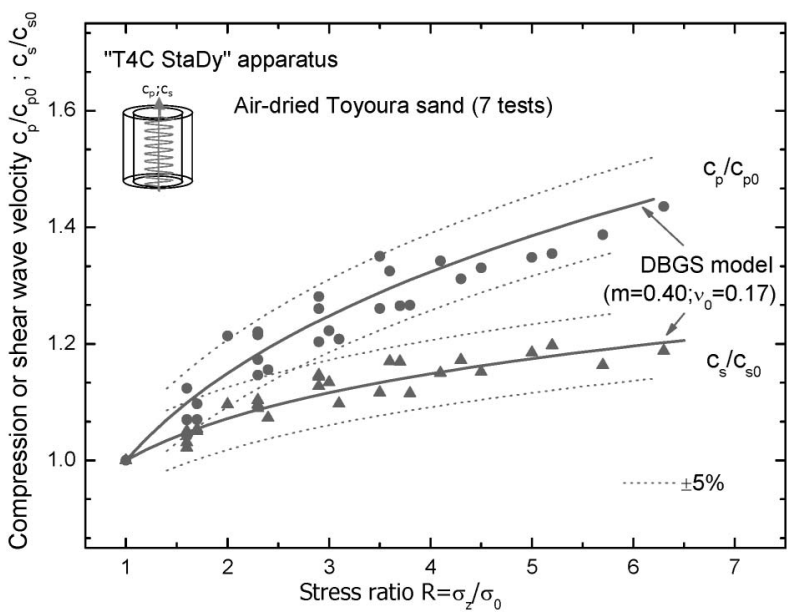

Fig. 24. Evolution of experimental compression and shear wave velocity $\left\{c_{\mathrm{p}} / c_{\mathrm{p} 0} ; c_{\mathrm{s}} / c_{\mathrm{s} 0}\right\}$ with stress ratio and simulations by DBGS model for TC tests performed on air-dried Toyoura sand ("'T4C StaDy" apparatus): $c_{\mathrm{p} 0} ; c_{\mathrm{s} 0}$ and $\sigma_{0}$ are respectively the compression, the shear wave velocity and the vertical stress at the initial isotropic state

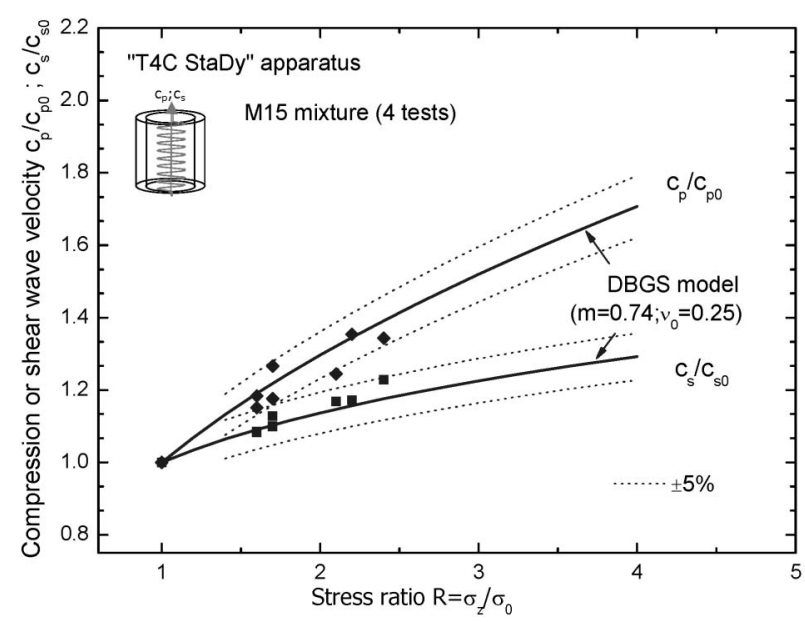

Fig. 25. Evolution of experimental compression and shear wave velocity $\left\{c_{\mathrm{p}} / c_{\mathrm{p} 0} ; c_{\mathrm{s}} / c_{\mathrm{s} 0}\right\}$ with stress ratio and simulations by DBGS model for TC tests performed on M15 mixture (“T4C StaDy" apparatus): $c_{\mathrm{p} 0} ; c_{\mathrm{s} 0}$ and $\sigma_{0}$ are respectively the compression, the shear wave velocities and the vertical stress at the initial isotropic state

sions leads to:

$$
\begin{gathered}
\rho c_{\mathrm{p}}^{2}=\frac{f(e) \sigma_{\mathrm{z}}^{\mathrm{m}}\left(v_{0}-1\right)}{v_{0}-1+v_{0}^{2}\left(1+R^{\mathrm{m}}\right)^{2} R^{-\mathrm{m}}} \\
\rho c_{\mathrm{s}}^{2}=\frac{f(e)}{2\left(1+v_{0}\right)} \sigma_{\theta}^{\mathrm{m} / 2} \sigma_{\mathrm{z}}^{\mathrm{m} / 2}
\end{gathered}
$$

with $R$ the stress ratio previously defined by $\sigma_{z} / \sigma_{\mathrm{r}}=\sigma_{z} / \sigma_{0}$ and by noting that $v_{\mathrm{r} \theta}=v_{\mathrm{rr}}=v_{0}$.

Therefore, one may notice that DBGS power coefficient $m$ can be deduced from the shear wave velocities evolutions with stress ratio:

$$
\frac{c_{\mathrm{s}}^{2}}{c_{\mathrm{s} 0}^{2}}=R^{\mathrm{m} / 2}
$$




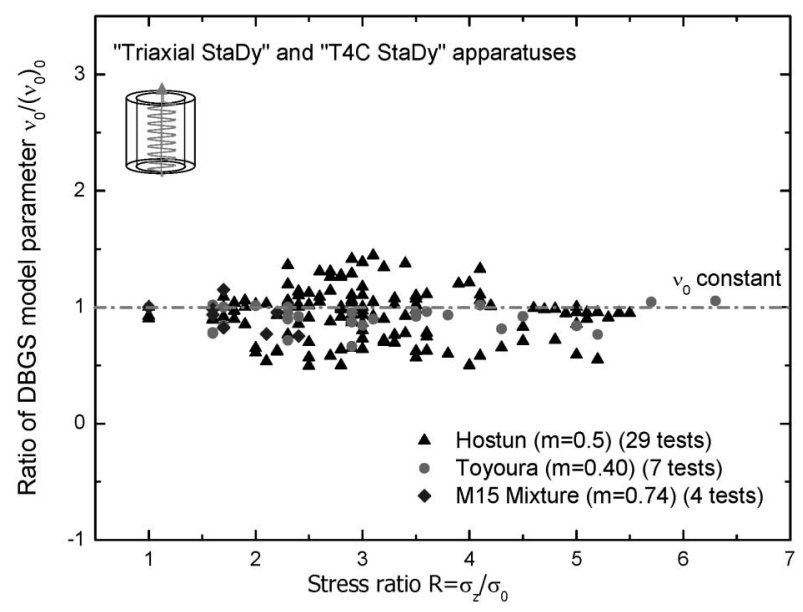

Fig. 26. Evolution of DBGS model parameter $v_{0} /\left[v_{0}\right]_{0}$ with shearing ([ $\left.v_{0}\right]_{0}$ is the value at the initial isotropic stress state) (relation 20) for all TC tests performed: $\sigma_{0}$ is the vertical stress value at the initial isotropic state

with $c_{\mathrm{s} 0}$ the initial shear wave velocity at the initial isotropic stress state.

Then, the two last constants $\left\{f(e) ; v_{0}\right\}$ may be determined by the system composed of the two Eqs. (16) and (17). However, since wave evolutions with shearing will be simulated, the determination of $f(e)$ can be skipped and the constant $v_{0}$ may be evaluated by the ratio $c_{\mathrm{p}} / c_{\mathrm{s}}$ as follows, considering Eqs. (16) and (17):

$$
\frac{c_{\mathrm{p}}^{2}}{c_{\mathrm{s}}^{2}}=\frac{4 R^{\mathrm{m} / 2}\left(v_{0}-1\right)\left(v_{0}+1\right)}{2\left(v_{0}-1\right)+v_{0}^{2}\left(1+R^{\mathrm{m}}\right)^{2} R^{-\mathrm{m}}}
$$

The following explicit solution $\left(v_{0}\right)$ may be derived from Eq. (19) (with $\chi=c_{\mathrm{p}}^{2} / c_{\mathrm{s}}^{2}$ ).

$$
v_{0}=\frac{\chi-\sqrt{\chi^{2}-4\left[\chi-2 R^{\mathrm{m} / 2}\right]\left[R^{\mathrm{m} / 2}-\chi\left(1+R^{\mathrm{m}}\right)^{2} R^{-\mathrm{m} / 2}\right]}}{4 R^{\mathrm{m} / 2}-\chi R^{-\mathrm{m}}\left(1+R^{\mathrm{m}}\right)^{2}}
$$

At the initial isotropic stress states $(R=1)$, one may notice that Eqs. (19) and (20) are naturally reduced to Eq. (3).

In Figs. 23, 24 and 25, are plotted, for respectively Hostun and Toyoura sands and M15 mixture, the evolutions with stress ratio of the experimental compression and shear wave velocities associated with the corresponding evolutions predicted by the DBGS model (i.e., Eqs. (16) and (17) respectively). In these figures, the "dynamically" determined constants $\left\{m ; v_{0}\right\}$ of the DBGS model are obtained respectively by Eq. (18) and by Eq. (20) at the initial isotropic stress state. One may notice that $\left\{m ; v_{0}\right\}$ values obtained dynamically remain close to the values obtained from static loadings (Simulations (Static Loadings)). From Figs. 23 to 25, it may be seen that simulations are in good accordance with experimental data. This agreement is consolidated by another additional fact: the parameter $\left(v_{0}\right)$ of the DBGS model, which may be seen as the (dynamically determined) Poisson's ratio at an initial isotropic stress state (see DBGS Model), is roughly constant while shearing as shown in Fig. 26. Some scattering may be noticed but

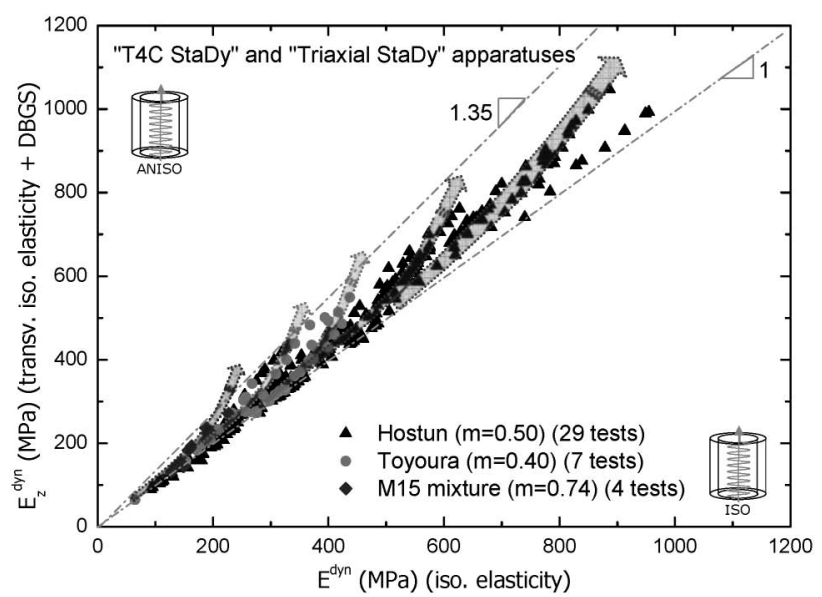

Fig. 27. Comparison between dynamically determined $E_{\mathrm{z}}^{\text {dyn }}$ (transv. iso. elasticity + DBGS model) and $E^{\text {dyn }}$ (iso. elasticity) for all TC tests performed in this study

Fig. 26 must be directly compared and put in a high contrast with Fig. 15, showing the increase of the dynamic Poisson's ratio determined within the assumption of an isotropic elastic behaviour, during otherwise the same conditions. Therefore, a transverse isotropic elastic behaviour may be considered as a more realistic assumption as the isotropic elastic one. From the analysis of all " dynamic" data the following average values were obtained for the parameter $v_{0}$ of the DBGS Model: Hostun sand, $v_{0}$ $=0.18$ (standard deviation $=0.06$ with $m=0.51$ ), Toyoura sand, $v_{0}=0.17$ (standard deviation $=0.025$ with $m=$ 0.40 ) and M15, $v_{0}=0.25$ (standard deviation $=0.02$ with $m=0.74)$.

In addition, from the above, it may be expected that a more direct and comprehensive comparison can be drawn between these two assumptions as explained in the next section.

\section{COMPARISON BETWEEN A TRANSVERSE ISOTROPIC AND AN ISOTROPIC ELASTIC ASSUMED BEHAVIOUR}

\section{Layout}

The application of DBGS model to wave propagation tests enables to draw a comparison between the two hypotheses of a transverse isotropic elastic behaviour and of an isotropic elastic behaviour, which $\left\{c_{\mathrm{p}} ; c_{\mathrm{s}}\right\}$ data may be analyzed within. As far as transverse isotropic elasticity is concerned (symmetry around the vertical ' $z$ ' axis), the symmetric compliance tensor linking stress and strain as in Eq. (5), takes the following general form given by Eq. (21). This tensor is characterized by five independent elastic parameters, let's say $\left\{E_{\mathrm{r}} ; E_{\mathrm{z}} ; v_{\mathrm{rr}} ; v_{\mathrm{rz}} ; G_{\theta \mathrm{z}}\right\}$, requiring therefore five independent measurements. However, as far as DBGS model is assumed to be relevant in predicting the evolution of these parameters, two independent measurements may be sufficient (as $\left\{c_{\mathrm{p}} ; c_{\mathrm{s}}\right\}$ ). 


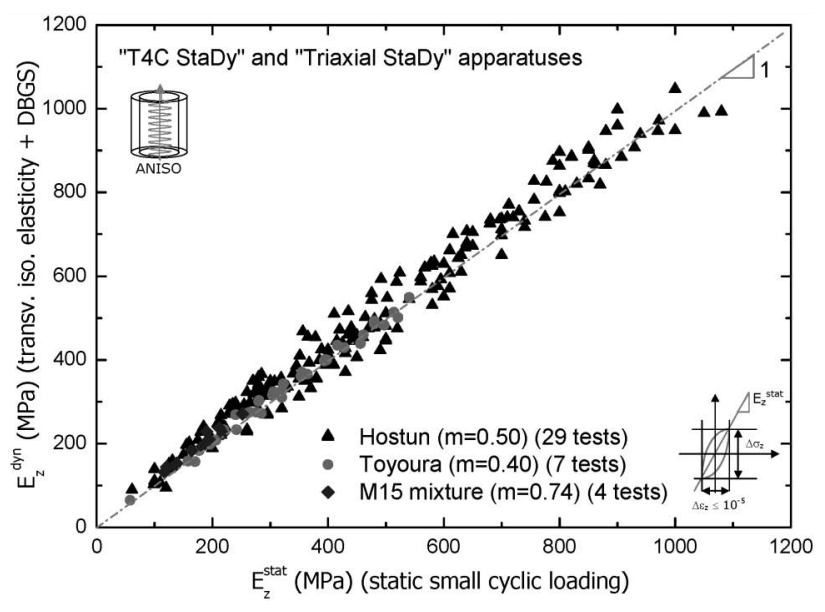

Fig. 28. Comparison between dynamically determined $E_{\mathrm{z}}^{\mathrm{dyn}}$ (transv. iso. elasticity + DBGS model) and statically determined $E_{\mathrm{z}}^{\text {stat }}$ (small cyclic loadings) for all TC tests performed in this study

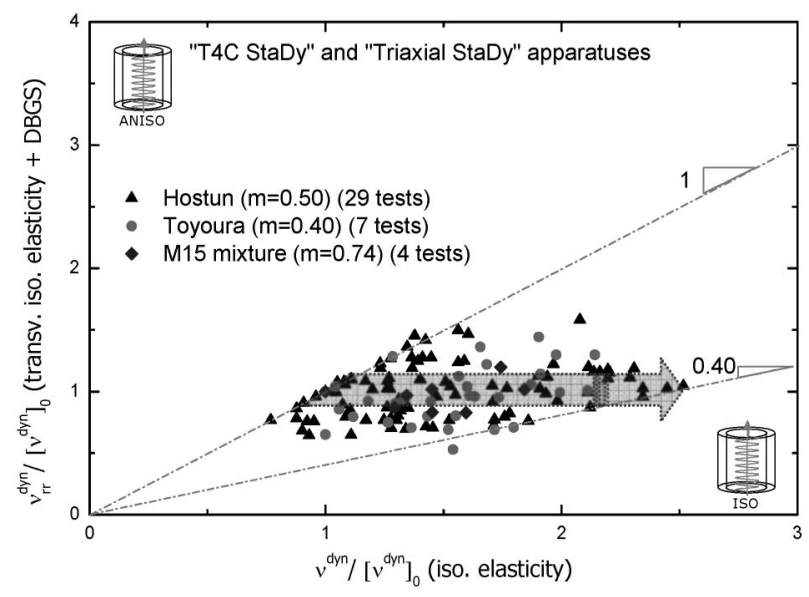

Fig. 29. Comparison between dynamically determined $v_{\mathrm{rr}}^{\mathrm{dyn}}\left(=v_{0}\right.$ (Eq. (13)), transv. iso. elasticity + DBGS model) and $v^{\mathrm{dyn}}$ (iso. elasticity) for all $\mathrm{TC}$ tests performed in this study ([ $]_{0}$ refers to values at the initial isotropic state)

$$
M=\left[\begin{array}{cccc}
\frac{1}{E_{\mathrm{r}}} & \frac{-v_{\mathrm{rr}}}{E_{\mathrm{r}}} & \frac{-v_{\mathrm{rz}}}{E_{\mathrm{z}}} & 0 \\
\frac{-v_{\mathrm{rr}}}{E_{\mathrm{r}}} & \frac{1}{E_{\mathrm{r}}}=\frac{1}{E_{\theta}} & \frac{-v_{\mathrm{rz}}}{E_{\mathrm{z}}} & 0 \\
\frac{-v_{\mathrm{rz}}}{E_{\mathrm{z}}} & \frac{-v_{\mathrm{rz}}}{E_{\mathrm{z}}} & \frac{1}{E_{\mathrm{z}}} & 0 \\
0 & 0 & 0 & \frac{1}{2 G_{\theta \mathrm{z}}}
\end{array}\right]
$$

Indeed, since the compliance elastic matrix predicted by the DBGS model can be fully determined by the three constants $\left\{f(e) ; m ; v_{0}\right\}$, the two independent sets of measurements $\left\{c_{\mathrm{p}} ; c_{\mathrm{s}}\right\}$ account for enough self sufficient data to determine these three constants ( $m$ value by the shear wave evolution with stress, and $\left\{f(e) ; v_{0}\right\}$ values by the data $\left\{c_{\mathrm{p}} ; c_{\mathrm{s}}\right\}$ at each investigation stage as mentioned in Application to Dynamic Loadings through Assumed Transverse Isotropic Elastic Behaviour). Therefore the

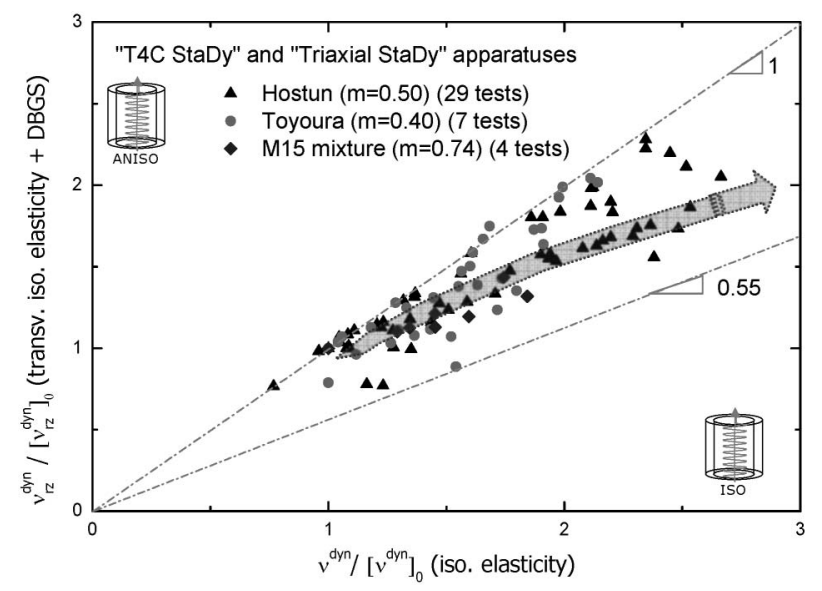

Fig. 30. Comparison between dynamically determined $v_{\mathrm{rz}}^{\text {dyn }}$ (transv. iso. elasticity + DBGS model) and $v^{\text {dyn }}$ (iso. elasticity) for all TC tests performed in this study ([ $]_{0}$ refers to values at the initial isotropic state)

five independent elastic parameters $\left\{E_{\mathrm{r}} ; E_{\mathrm{z}} ; v_{\mathrm{rr}} ; v_{\mathrm{rz}} ; G_{\theta \mathrm{z}}\right\}$ may be determined and compared, at each investigation stage with the two independent elastic parameters (let's say $\{E ; v\}$ ) deduced from an isotropic elastic assumed behaviour (Results from Dynamic Loadings). In the next two sections, will be respectively compared the dynamically determined vertical Young's modulus ( $E_{z}^{\text {dyn }}$, within the framework of a transverse isotropic elastic behaviour and the DBGS model) with the dynamically determined isotropic elastic Young's modulus ( $E^{\text {dyn }}$, Results from Dynamic Loadings and Comparison between Static and Isotropic Dynamic Elastic Moduli), and the dynamically determined Poisson's ratio $\left\{v_{\mathrm{rr}}^{\text {dyn }} ; v_{\mathrm{rz}}^{\text {dyn }}\right\}$ (transverse isotropic elasticity + DBGS) with the isotropic Poisson's ratio $v^{\text {dyn }}$ (isotropic elasticity, Results from Dynamic Loadings).

\section{Young's Modulus}

At each investigation stage, the vertical Young's modulus $\left(E_{z}^{\text {dyn }}\right)$ may be estimated dynamically considering a transverse isotropic elastic behaviour and the DBGS model, by the following expression (derived from Eqs. (14) and (16)):

$$
E_{\mathrm{z}}^{\mathrm{dym}}=\rho c_{\mathrm{p}}^{2} \frac{v_{0}-1+v_{0}^{2}\left(1+R^{\mathrm{m}}\right)^{2} R^{-\mathrm{m}}}{v_{0}-1}
$$

In expression (22), $m$ value is given by Eq. (18) and previously reported in Figs. 23 to 26 . The $v_{0}$ value may be determined by Eq. (20) at each investigation stage from the values of $\left\{c_{\mathrm{p}} ; c_{\mathrm{s}}\right\}$. In Fig. 27 is shown the direct comparison between $\left(E_{\mathrm{z}}^{\mathrm{dyn}}\right)$ and the isotropic $\left(E^{\mathrm{dyn}}\right)$ (see Results from Dynamic Loadings and Comparison between Static and Isotropic Dynamic Elastic Moduli, isotropic elasticity assumed) for all TC tests performed during this study. At the initial isotropic stress state $(R=$ $1)$, the two moduli $\left\{E_{\mathrm{z}}^{\mathrm{dyn}} ; E^{\mathrm{dyn}}\right\}$ are obviously equivalent (see Eqs. (22) and (1) to (3)) so that data points follow the slope 1. But, as shearing increases, difference got much 
more significant reaching around $30 \%$ for stress ratios close to failure. As one may expect, since $E^{\text {dyn }}$ can be seen as an average of the Young's moduli in the different directions, the isotropic elastic assumption underestimates the value of the true vertical Young's modulus $E_{z}^{\text {dyn }}$ (when considering an anisotropic behaviour through DBGS model). As a consequence (see Figs. 27 and 16), a much more consistent agreement is reached between the dynamic anisotropically determined $E_{\mathrm{z}}^{\mathrm{dyn}}$ and the static $E_{\mathrm{z}}^{\text {stat }}$ derived from small cyclic loading in direction ' $z$ " as shown in Fig. 28.

\section{Poisson's Ratio}

A comparison may also be drawn between the elastic parameters $\left\{v_{\mathrm{rr}}^{\text {dyn }} ; v_{\mathrm{rz}}^{\text {dyn }}\right\}$ dynamically determined through a transverse isotropic elastic assumption associated with the DBGS model and the unique isotropic Poisson's ratio $v^{\text {dyn }}$.

In Fig. 29 is shown the comparison between $v_{\mathrm{rr}}^{\mathrm{dyn}}$ and $v^{\text {dyn }}$ for all TC tests performed on the different materials. Keeping in mind that the Poisson's ratio $v_{\mathrm{rr}}^{\mathrm{dyn}}$ is equivalent to the DBGS model constant $v_{0}$ (as expressed by Eqs. (9) and (13)), $v_{\mathrm{rr}}^{\mathrm{dyn}}$ values are thus obtained from Eq. (20) with the $m$ values previously determined (see Young's Modulus and Application to Dynamic Loadings through Assumed Transverse Isotropic Elastic Behaviour). Therefore, in Fig. 29 may also be seen that this parameter $v_{0}$ stay roughly constant while shearing (as illustrated by the dash arrows) leading to a strong overestimation of $v_{\mathrm{rr}}^{\mathrm{dyn}}$ by an assumed isotropic elastic behaviour. In Fig. 30 is reported the comparison between $v_{\mathrm{rz}}^{\mathrm{dyn}}$ and $v^{\mathrm{dyn}} \cdot v_{\mathrm{rz}}^{\mathrm{dyn}}$ may be determined by Eq. (13) considering the $v_{0}$ values inferred from Eq. (20) (at each investigation stage) and similarly as before, the $m$ values from Eq. (18). Increasing difference between $v^{\text {dyn }}$ and $v_{\mathrm{rz}}^{\text {dyn }}$ with shearing may be seen. This is illustrated by the dash arrows in Fig. 30. The Poisson's ratio values $v_{\mathrm{rz}}$ are also significantly overestimated by an assumed isotropic elastic behaviour.

\section{CONCLUSIONS AND FINAL REMARKS}

From the TC tests results presented in this paper the following conclusions may be derived:

i) The evolution of statically and dynamically determined elastic moduli (vertical Young's modulus, shear modulus) with stress state can be correctly fitted with power laws of the considered mobilized stresses. This is in accordance with numerous previous studies, assuming otherwise a traditional isotropic elastic behaviour for dynamic tests interpretation.

ii) Despite higher incertitude, an increasing tendency of static Poisson's ratios with stress level may be seen, in a consistent manner considering the two different apparatuses.

iii) Statically and dynamically determined shear moduli are in very good accordance whereas some discrepancy may be noticed as far as Young's modulus is concerned.

iv) The overly simplifying isotropic elastic behaviour (assumed) may be responsible for this discrepancy.

v) The hypo-elastic anisotropic model DBGS is found to be relevant to predict the evolution of "static" Young and shear moduli, as well as the evolution of compression and shear wave velocities with shearing considering otherwise a transverse isotropic behaviour.

vi) By means of the DBGS model, in the dynamic tests interpretation, a comparison between the assumptions of an anisotropic elastic behaviour and an isotropic elastic behaviour (previously considered) can be drawn. The comparison reveals the significant underestimation of "dynamic" vertical Young's modulus and the strong overestimation of "dynamic", Poisson's ratios by an oversimplifying (assumed) isotropic elastic behaviour.

vii) A good concordance is thus obtained on the vertical Young's modulus between the static and the dynamic methods as far as a relevant anisotropic (DBGS model) elastic behaviour is assumed for dynamic tests.

It should be emphasized that the more realistic assumption of an anisotropic elastic behaviour in the dynamic test interpretation is taken into account without additional experiments. For this, the DBGS model is considered with only two constants to be determined, the general approach presented in this paper being basically free of the determination of the third constant $f(e)$ and its expression in terms of void ratio, $e$. This however remains limited to small variations in the void ratio. For larger variations in $e$, the same approach can be considered but requires the determination of $f(e)$ (with otherwise the resolution of system composed of Eqs. (16) and (17)). Applications to practical cases can be found for example in cross-hole experiments performed largely in the field. These experiments basically provide the profile of compression and shear wave velocities with depth. Given the above, when necessary, an anisotropic elastic behaviour can be smoothly considered, resulting in a more accurate determination of soil properties. And in case of saturated natural soils, soils skeleton properties can be adequately represented by the DBGS model and the latter approach generalized by considering otherwise the compressibility of the pore fluid. Details on such studies for a french nuclear plant site have been reported in Duttine (2005) and in Di Benedetto et al. (2005).

\section{ACKNOWLEDGEMENTS}

The authors wish to thank the French national company Electricité de France (EDF) for their collaboration and financial support during this study.

\section{REFERENCES}

1) Ackerly, S. K., Hellings, J. E. and Jardine, R. J. (1987): Discussion on A new device for measuring local axial strains on triaxial specimens, Géotechnique, 37(3), 413-417.

2) Brignoli, E. G. M., Gotti, M. and Stokoe, K. H. (1996): Measurement of shear waves in laboratory specimens by means of piezoelectric transducers, Geotech. Test. J., 19(4), 384-397. 
3) Burland, J. B. and Symes, M. (1982): A simple axial displacement gauge for use in triaxial apparatus, Géotechnique, 32(1), 62-65.

4) Darve, F. (1978): Une formulation incrémentale des lois rhéologiques. Application aux sols, Thèse d'Etat, IM Grenoble (in French).

5) Di Benedetto, H. (1997): Viscous effect and anisotropy for sand, Panel Discussion I.1 of the 15th ICSMFE, Hamburg, Balkema 4.

6) Di Benedetto, H., Cazacliu, B., Boutin, C., Doanh, T. and Touret, J. P. (1997a): Comportement des sables avec rotation d'axes: nouvel appareil couvrant quatre décades de déformation, Proc. 14th ICSMFE., Hamburg, Balkema, I, 279-282 (in French).

7) Di Benedetto, H. and Tatsuoka, F. (1997b): Small strain behaviour of geomaterials: Modelling of strain rate effects, Soils and Foundations, 37(2), 127-138.

8) Di Benedetto, H., Cazacliu, B., Geoffroy, H. and Sauzéat, C. (1999): Sand behaviour in the very small to medium strain domains, Proc. IS on Pre-failure Def. Char. of Geomat. (eds. by Jamiolkowski et al.), Torino, Balkema, 89-96.

9) Di Benedetto, H., Geoffroy, H. and Sauzéat, C. (2001): Viscous and non-viscous behaviour of sand obtained from hollow cylinder tests, Advanced Laboratory Stress-strain Testing of Geomaterials (ed. by Tatsuoka et al.), Rotterdam; Balkema, 212-221.

10) Di Benedetto, H., Tatsuoka, F., Lo Presti, D., Sauzéat, C. and Geoffroy, H. (2003): Time effects on the behaviour of geomaterials, Keynote Lecture, International Symposium, Lyon, 2003, II, 63.

11) Di Benedetto H., Geoffroy H., Duttine A., Sauzeat, C. and Chau, B. (2005): Anisotropic behaviour of soils and site investigation based on wave propagation tests, Proc. 16th ICSMGE, Osaka (in French).

12) Duttine, A. (2005): Comportement des sables et des mélanges sable/argile sous sollicitations statiques et dynamiques avec et sans «rotation d'axes », PhD Thesis, ENTPE (in French).

13) Duttine, A., Di Benedetto, H. and Pham Van Bang, D. (2006) Viscous properties of dry sands and mixtures of sand/clay from hollow cylinder tests, Proc. ISRoma 06, March 15-16th (in press).

14) Ezaoui, A., Di Benedetto, H. and Pham Van Bang, D. (2006): Anisotropic behaviour of sand in the small strain domain, Experimental measurements and modelling, Proc. ISRoma 06, March 15-16th (in press).

15) Flavigny, E., Desrues, J. and Palayer, B. (1990): Note technique: le sable d'Hostun RF. Revue Française de Géotechnique, 53, 67-70 (in French).

16) Goto, S., Tatsuoka, F., Shibuya, S., Kim, Y. S. and Sato, T. (1991): A simple gauge for local small strain measurements in the laboratory, Soils and Foundations, 31(1), 169-180.

17) Hardin, B. O. and Blandford, G. E. (1989): Elasticity of particulate materials, J. Geotech. Engrg., ASCE, 115(6), 788-805.

18) Hicher, P. Y. (1996): Elastic properties of soils, Journal of Geotech. Engrg., 122(8), 641-648.

19) Hight, D. W., Gens, A. and Symes, M. J. (1983): The development of a new hollow cylinder apparatus for investigating the effects of principal stress rotation in soils, Géotechnique, 33(4), 355-384.

20) Hird, C. C. and Yung, P. C. Y. (1989): The use of proximity transducers for local strain measurements in triaxial tests, Geotech. Test. J., 12(4), 292-296.

21) Hoque, E. (1996): Elastic deformation of sands in triaxial tests, PhD Thesis, University of Tokyo.

22) Hoque, E. and Tatsuoka, F. (1998): Anisotropy in the elastic deformation of granular materials, Soils and Foundations, 38(1).

23) Jardine, R. J., Kuwano, R., Zdravkovic, L. and Thornton, C. (1999): Some fundamental aspects of the pre-failure behaviour of granular soils, Keynote Lecture in IS on Pre-failure Deformation Characteristics of Geomaterials, Torino, II, 1077-1111.

24) Kuwano, R., Connolly, T. M. and Jardine, R. J. (1999): Anisotropic stiffness measurements in a stress-path triaxial cell, Geotech. Test. J., 23(2), 141-157.

25) Lo Presti, D., Pallara, O., Lancelotta, R., Amandi, M. and Maniscalco, R. (1993): Monotonic and cyclic loading behaviour of two sands at small strains, Geotech. Test. J., 16(4), 409-424.

26) Lo Presti, D., Jamiolkowski, M., Pallara, O., Cavallaro, A. and Perroni, S. (1997): Shear modulus and damping of soils, Geotechnique, XLVII (3).

27) Modoni, G., Flora, A., Mancuso, C., Viggiani, C. and Tatsuoka, F. (2000): Evaluation of gravel stiffness by pulse wave transmission tests, Geotech. Test. J., 23(4), 506-520.

28) Pham Van Bang, D., Di Benedetto, H., Duttine, A. and Ezaoui, A. (2006): Viscous behaviours of dry sand, Int. J. Anal. Num. Meth. Geomech. (in press).

29) Sayao, A. and Vaid, Y. P. (1991): A critical assessment of stress nonuniformities in hollow cylinder tests specimens, Soils and Foundations, 31(1), 60-72.

30) Stokoe, K. H. II, Hwang, S. K. and Lee, J. N.-K. (1995): Effects of various parameters on the stiffness and damping of soils at small strains, Proc. IS Hokkaido'94, 2, 785-816.

31) Tatsuoka, F. and Shibuya, S. (1991): Deformation characteristics of soils and rocks from field and laboratory tests, KNL Lecture, Proc. 9th Asian Reg. Conf. SMFE, Bangkok, 2, 101-170.

32) Tatsuoka, F., Teachavorasinsun, S., Dong, J., Kohata, Y. and Sato, T. (1994). Importance of measuring local strains in cyclic triaxial tests on granular materials, Dynamic Geotech. Test. II, ASTM STP 1213 (eds. by Ebelhar, R., Drnevich, V., Kutter, B.), Philadelphia, 288-302.

33) Tatsuoka, F. and Kohata, Y. (1995): Stiffness of hard soils and soft rocks in engineering applications, Keynote Lecture IS Hokkaido 1994, 2, 947-1063.

34) Tatsuoka, F., Jardine, R. J., Lo Presti, D., Di Bendetto, H. and Kodaka, T. (1999): Characterizing the pre-failure deformation properties of geomaterials, Theme Lecture, Proc. 14th ICSMFE, Hamburg, 4, 2129-2164.

35) Viggiani G. and Atkinson, J. H. (1995): Stiffness of fine grained soils at very small strains, Geotechnique, 45(2), 249-26. 